\title{
(ब)
}

AUTARQUIA ASSOCIADA À UNIVERSIDADE DE SÃO PAULO

\section{CARACTERIZAÇÃO DO FILME RADIOCRÔMICO GAFCHROMICTM MODELO EBT3 PARA USO EM BRAQUITERAPIA}

\author{
Jessica Luvizotto
}

Dissertação apresentada como parte dos requisitos para obtenção do Grau de Mestre em Ciências na Área de Tecnologia Nuclear - Reatores

Orientador:

Prof. Dr. Helio Yoriyaz 


\title{
INSTITUTO DE PESQUISAS ENERGÉTICAS E NUCLEARES
}

Autarquia associada à Universidade de São Paulo

\section{CARACTERIZAÇÃO DO FILME RADIOCRÔMICO GAFCHROMICTM MODELO EBT3 PARA USO EM BRAQUITERAPIA}

\author{
Jessica Luvizotto
}

Dissertação apresentada como parte dos
requisitos para obtenção do Grau de
Mestre em Ciências na Área
de Tecnologia Nuclear-Reatores

Orientador:

Prof. Dr. Helio Yoriyaz

Versão Corrigida

Versão Original disponível no IPEN

São Paulo

2015 
Dedicatória

Dedico esse trabalho aos meu pais, Rosmari e Edevar, minhas irmãs, Jaqueline e Júlia, e ao meu futuro marido, Arthur, todo o meu amor 
Agradecimentos

Gostaria de agradecer os meus pais, Rosmari e Edevar, e as minhas irmãs, Jaqueline e Júlia, pelo carinho, amor, compreensão e apoio. Principalmente a minha mãe que nesses dois anos acordou de madrugada que me levou até o ponto onde passava o fretado para o IPEN ou para a rodoviária para fazer os experimentos em Botucatu. E ao meu pai que me ajudou muito na reta final da minha dissertação.

Ao meu futuro marido, Arthur, pelo amor e compreensão nesses dois anos afastados.

Agradeço ao meu orientador Prof. Dr. Hélio Yoriyaz, pela oportunidade de concretização deste trabalho, pela orientação dedicada, pela paciência e pelos ensinamentos durante esses dois anos, que me ajudaram na realização desse trabalho.

Ao departamento de radioterapia do Hospital das Clínicas da Faculdade de medicina de São Paulo - USP, pelo acesso a braquiterapia e ao scanner e pelos filmes radiocrômicos.

A todos os bolsistas do CEN, Talita, Paula, Gabriel, Fabio, Tássio, Rodrigo, Vinicius, Murilo, Luiza, Margarida pela amizade, incentivo, paciência, pelos momentos de alegria e por experiências trocadas. Agradeço em especial o Gabriel pela ajuda em relação às normas, artigos e pela parte computacional, a Paula em relação aos filmes, a Talita pela ajuda com a teoria do método de Monte Carlo e com as imagens digitalizadas. 
Ao Instituto de Pesquisas Energéticas e Nucleares (IPEN/CNEN) por dada a infraestrutura e pelo suporte financeiro a Comissão Nacional de Energia Nuclear (CNEN) e a Fundação de Amparo à Pesquisa do Estado de São Paulo.

Ao Hospital das Clínicas da Faculdade de Medicina de Botucatu - UNESP, em especial ao Prof. Dr. Marco Antonio Rodrigues Fernandes por me ajudar e possibilitar o acesso para realização dos experimentos.

Um agradecimento especial a Deus por estar sempre ao meu lado me iluminam e também por colocar em meu caminho pessoas tão especiais que me ajudaram e ainda me ajudam nas minhas escolhas. 


\title{
CARACTERIZAÇÃO DO FILME RADIOCRÔMICO GAFCHROMICTM MODELO EBT3 PARA USO EM BRAQUITERAPIA
}

\author{
Jessica Luvizotto
}

\section{Resumo}

\begin{abstract}
A braquiterapia é a modalidade de tratamento radioterápico que utiliza fontes radioativas seladas a uma distância curta do tumor, diminuindo o risco de aplicação de uma dose indesejável em tecidos sadios adjacentes. Para que a braquiterapia seja confiável, é necessário estabelecer um programa de práticas dosimétricas visando a determinação da dose ideal de radiação para esta prática radioterápica. Neste trabalho apresenta a aplicação de duas metodologias destinadas à dosimetria utilizando filmes radiocrômicos. Medidas experimentais foram realizadas com filmes EBT3 em objetos simuladores composto de material homogêneo e heterogêneo (pulmão, osso e tecidos moles) construídos especialmente para medidas de dose em braquiterapia. Os processamentos e analises das imagens resultantes do procedimento experimental foram realizados com o software IMAGEJ e MATLAB. Os resultados foram avaliados a partir de comparações medidas experimentais de dose e obtidas por simulações pelo Método de Monte Carlo.
\end{abstract}




\title{
CHARACTERISTICS OF THE FILM RADIOCHROMIC GAFCHROMIC EBT3 MODEL FOR USE IN BRACHYTHERAPY
}

\author{
Jessica Luvizotto
}

\begin{abstract}
Brachytherapy is a radiotherapy treatment modality using radioactive sealed sources within walking distance of the tumor, reducing the risk of applying an unwanted dose to adjacent healthy tissues. For brachytherapy is reliable, it is necessary to establish a dosimetric practices program aimed at determining the optimal dose of radiation for this radiotherapy practice. This paper presents the application of two methodologies for the dosimetry using radiochromic movies. Experimental measurements were performed with EBT3 movies phantoms consisting of homogeneous and heterogeneous material (lung, bone and soft tissue) built especially for dose measurements in brachytherapy. The processing and analysis of the resulting images of the experimental procedure were performed with ImageJ software and MATLAB. The results were evaluated from comparisons dose of experimental measurements and simulations obtained by the Monte Carlo method.
\end{abstract}




\section{Sumário}

1 Introdução 1

2 Objetivo 4

3 Revisão Bibliográfica $\quad 6$

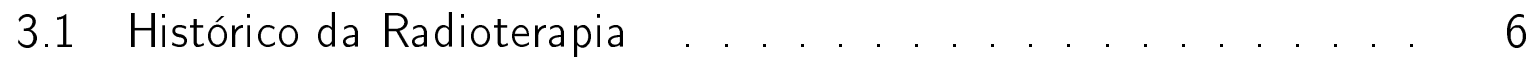

3.1.1 Radioterapia . . . . . . . . . . . . . . . . . 12

3.1.1.1 Teleterapia . . . . . . . . . . . . . . 13

3.1.2 Braquiterapia ............. . . 14

3.1 .2 Dosimetria . . . . . . . . . . . . . . 17

3.1.2.1 Fundamento Teórico . . . . . . . . . . . . 18

3.1.2.2 Sistemas Dosimétricos . . . . . . . . . . . 19

3.1.2.3 Cálculos Dosimétricos . . . . . . . . . . 20

3.1.2.4 Dosímetros . . . . . . . . . . . . . . 24

4 Materiais e Métodos 36

4.1 Dados Experimentais . . . . . . . . . . . . . . . 37 
4.1.1 Materiais heterogêneos para fonte de ${ }^{192} \operatorname{lr} \ldots \ldots 37$

4.1.2 Estudo comparativo entre a calibração de uma fonte de ${ }^{192}$ Ir e um Acelerador Linear . . . . . . . . . . . . . . . 40

4.1.3 Materiais heterogêneos para a fonte de ${ }^{60} \mathrm{Co} \ldots . . . . \quad 41$

4.2 O filme GAFCHROMIC ${ }^{\mathrm{TM}}$ modelo EBT3 . . . . . . . . . . . 42

4.3 Fontes . . . . . . . . . . . . . . . . . . . . . . . . . 44

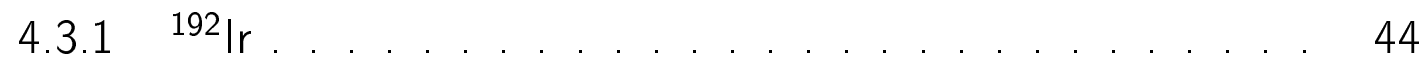

4.3.2 Unidades de telecobaltoterapia . . . . . . . . . . 46

4.3.3 Acelerador Linear . . . . . . . . . . . . . . . . . . 47

4.4 Materiais simuladores de tecido humano . . . . . . . . . . 47

4.5 Scanner . . . . . . . . . . . . . . . . . . . . . . . . . 49

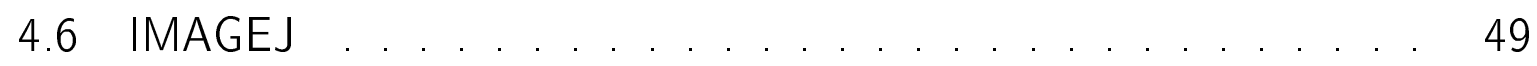

4.7 MATLAB . . . . . . . . . . . . . . . . . . . . . . . . . . 50

4.8 Linearizações . . . . . . . . . . . . . . . . . . . . . . . . . . . . . . . . 52

4.9 Multicanais . . . . . . . . . . . . . . . . . . . . . . 54

4.10 Método de Monte Carlo . . . . . . . . . . . . . . . . . . . 59

4.10.1 Teoria do Modelo . . . . . . . . . . . . . . . . . 60

4.10 .2 O código MCNP5 . . . . . . . . . . . . . . . . . 61

4.10 .3 Simulação do Experimento . . . . . . . . . . . . . . . 64

5 Resultados e Discussões $\quad 67$

5.1 Materiais heterogêneos para fonte de ${ }^{192} \mid \mathrm{r} \ldots$. . . . . . . . 67 
5.2 Estudos comparativo entre a calibração de uma fonte de ${ }^{192}$ Ir e um Acelerador Linear . . . . . . . . . . . . . . . . . . . . 70

5.3 Materiais heterogêneos para a fonte de ${ }^{60} \mathrm{Co} \ldots . . . . .7676$

6 Conclusão 


\section{Lista de Tabelas}

3.1 Propriedades físicas dos radionuclídeos aplicados em braquiterapia

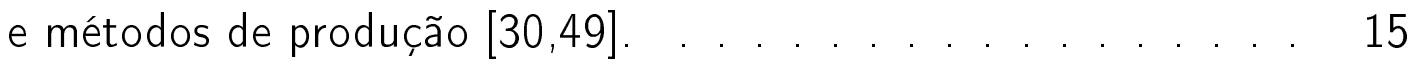

3.2 Propriedades físicas dos radionuclídeos aplicados em braquiterapia $[30,49] \ldots \ldots \ldots \ldots \ldots \ldots$

4.1 Tabela 4.1 - Densidade e composição dos materiais tecido-equivalente. 39

4.2 Densidade e composição dos materiais tecido-equivalente. . . . 42

5.1 Incertezas obtidas a partir dos resultados experimentais e da lite-

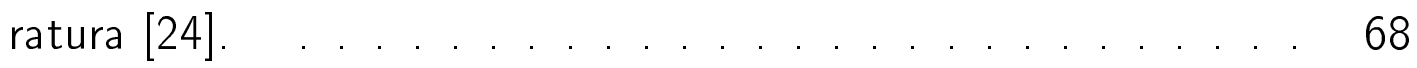

5.2 Valores de dose experimentais e calculados em cGy para diferentes materiais.

5.3 Valores de dose experimentais e calculados em Gy para diferentes materiais.

5.4 Diferenças percentuais na dose para diferentes materiais. 


\section{Lista de Figuras}

3.1 a) Foto de Wihelm Conrad Röentgen. b)Diapositiva da radiográfia da mão da esposa de Röentgen, Anna Bertha Ludwing, tirada em 22/12/1895 [49]. . . . . . . . . . . . . . . . 7

3.2 Ilustração da geometria assumida no formalismo do cálculo da

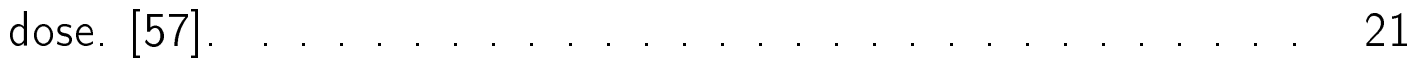

3.3 Desenho da Câmara de Ionização [21] . . . . . . . . . . . 30

4.1 Placas de PMMA e os cilindros de tecido-equivalentes inseridos no centro com o catéter da fonte de ${ }^{192}$ Ir logo abaixo.

4.2 Placas de água sólidas e catéter da fonte de ${ }^{192} \mathrm{Ir}$ inserido no centro da placa de PMMA . . . . . . . . . . . . . . 40

4.3 Unidade de telecobaltoterapia e as placas de acrílico com o filme que foram irradiados. . . . . . . . . . . . . . . . 41

4.4 Curva sensitométrica. [21] . . . . . . . . . . . . . . . . 43

4.5 Desenho do fio irídio [30]. . . . . . . . . . . . . . . . . 45 
4.6 a) Componentes do objeto simulador para medidas de dose com filme EBT3 e b) materiais simuladores de tecido humano. . . . .

4.7 Curva sensitométrica do filme radiocrômico. A linha pontilhada simula uma reposta linear [29] . . . . . . . . . . . . . . . . 53

4.8 Modelagem geométrica do experimento com fonte de Irídio. . . . 65

4.9 Modelagem geométrica do experimento com fonte de Cobalto. . 66

5.1 Curvas de calibração usando: a) linearização e b) multicanais. . . 68

5.2 Curvas de calibração obtidas com método dos três canais (a) e com o método da linearização (b) para dois tipos de fonte: acelerador linear de $6 \mathrm{MV}$ e fonte de ${ }^{192} \mathrm{Ir}$.

5.3 Razão entre as doses obtidas experimentalmente e os valores esperados para a calibração realizada com duas fontes distintas. a) Acelerador linear 6 MV (teleterapia); b) ${ }^{192} \operatorname{Ir}$ (braquiterapia). .

5.4 Distribuição de dose obtida para os três canais (RGB) sem correção (linha superior) e após a correção.

5.5 Perfis de dose antes (a) e após (b) a correção.

5.6 Doses obtidas com o método dos três canais (primeira coluna), da linearização (segunda coluna) e a razão entre os resultados (terceira coluna)

5.7 Curvas de calibração obtidas com método dos três canais (a) e com o método da linearização (b) 


\section{Capítulo 1}

\section{Introdução}

A braquiterapia é uma modalidade de terapia radioterápica que utiliza uma ou várias fontes radioativas seladas dispostas a distâncias curtas do tumor, através de aplicações intersticiais, intracavitárias ou superficiais [1]. A dose é liberada continuamente, durante um curto período de tempo (implantes temporários) ou sobre a vida média da fonte até um completo decaimento (implante permanente). Em um serviço típico de radioterapia cerca de 10 a 20\% dos pacientes são tratados pela braquiterapia $[2,3]$. A braquiterapia pode ser empregada para qualquer neoplasia acessível a uma fonte radioativa, sendo indicada rotineiramente no tratamento das neoplasias do colo e do corpo uterino, da cabeça e pescoço, da região perineal e dos tecidos moles.

A braquiterapia de alta taxa de dose está passando por um período de desenvolvimento técnico significativo numa mudança das tradicionais imagens em 2D, para imagens em 3D e tratamentos de planejamentos-invertidos. Os métodos 
tradicionais de controle de qualidade com testes simplistas do desempenho dos equipamentos não são suficientes para a prática de braquiterapia moderna [4].

As técnicas de dosimetria na braquiterapia em geral têm recebido maior atenção desde 2009, quando um número de pacientes recebeu tratamento braquiterapia inadequado, pela braquiterapia de baixa taxa de dose de má qualidade. Neste caso também houve confusão nas unidades da fonte e entrada incorreta dos sistemas de planejamento de tratamento deteriorações relacionados com a posições de paradas inesperadas da fonte em aplicadores de anel e a mudanças no software de controle para as fontes de braquiterapia de alta taxa de dose [4].

O desafio para as medidas em braquiterapia é particularmente difícil devido aos gradientes de dose e em ordens de magnitude de variação na deposição em toda a região de interesse. Para uma dosimetria de boa qualidade são necessárias medidas precisas e rígidas. O filme radiocrômico Gafchromic é um dosímetro 2D com potencial para medida de dose de braquiterapia [4]. Filmes radiocrômicos são auto reveladores que os filmes radiográficos possuem uma resolução espacial mais alta e podem ser utilizados para dosimetria em regiões com alta dose. As vantagens do uso deste tipo de dosímetro são: a) fraca dependência com a energia na faixa de $\mathrm{keV}$ a $\mathrm{MeV}[7,8], \mathrm{b})$ o fato de ser um material tecidoequivalente quando comparado ao corpo humano e c) a possibilidade de se obter uma relação linear dose versus resposta para uma determinada faixa de dose [9]. Os filmes comumente utilizados são os da marca Gafchromic, produzidos pela International Specialty Products (ISP) [5]. 
Essas características combinadas fazem do filme radiocrômico uma excelente escolha para a verificação da dose em tratamentos complexos com feixes de incidência oblíqua ou incidência normal [10]. Ao rever os métodos de dosimetria experimentais para braquiterapia conclui-se que o filme radiocrômico é uma técnica promissora, e que este tipo de filme deve ser considerado "em desenvolvimento neste momento" por causa da não-uniformidade e artefatos de scanner. 


\section{Capítulo 2}

\section{Objetivo}

Observado o aspecto promissor de emprego dessa técnica radioterápica e, o estágio atual de seu desenvolvimento e emprego, o presente trabalho visou contribuir no tema, investigando a caracterização dosimétrica do filme radiocrômico EBT3 recentemente lançado no mercado internacional em fontes de braquiterapia desenvolvendo um estudo dosimétrico para uso específico desse em braquiterapia de alta taxa de dose, HDR. As pesquisas foram desenvolvidas no ICESP (Instituto do Câncer do Estado de São Paulo) e no COI (Clínicas Oncológicas Integradas, Barra da Tijuca, Rio de Janeiro) empregou com sistema de pós-carga por controle remoto computadorizado (microSelectron-HDR Nucletron $B$ ), cuja fonte de radiação é uma semente de Irídio-192. As irradiações com fonte de Cobalto-60 foram realizadas no Hospital das Clínicas da Faculdade de Medicina de Botucatu - UNESP.

A caracterização dosimétrica do filme EBT3 consistiu na determinação da 
curva reposta do filme, tais como, análise da dependência energética, orientação e posicionamento de escaneamento do filme, tamanho e proporção do filme. Os resultados experimentais foram obtidos através de medidas de dose em experimentos conduzidos em objetos simuladores homogêneos e heterogêneos compostos de materiais simuladores de tecido humano. A avaliação destes resultados foi realizada a partir de comparações com valores de dose obtidas por simulações pelo Método de Monte Carlo. 


\section{Capítulo 3}

\section{Revisão Bibliográfica}

Este capítulo apresenta uma revisão bibliográfica das modalidades e procedimentos radioterápicos, bem como, alguns métodos de medida de dose utilizados em braquiterapia.

\subsection{Histórico da Radioterapia}

Em 8 de novembro de 1895, Wihelm Conrad Roentgen (Figura 3.1a), professor de física da Universidade de Würzburg, na Alemanha, reproduziu os experimentos com raios catódicos, produzindo estes raios em tubo de vidro envacuado, com dois eletrodos metálicos onde se aplicava uma diferença de potencial Roentgen embrulhou o tubo com papel preto para que a luminescência muito forte não atrapalhasse a sua visão e verificou que mesmo a uma distância de 2 m a luminescência continuava. Ainda, notou que toda vez que desligava a luminescência 
desaparecia. O Roentgen concluiu que este fenômeno não era efeito dos raios catódicos. Os novos raios eram mais penetrantes que os raios catódicos e não sofriam desvio com campo magnético (Figura 3.1b). Esses raios desconhecidos, mas de existência comprovada, foram chamados de "Raios X".

Roentgen se empenhou em descobrir a natureza dos raios $X$, porém sem sucesso sendo, somente em 1912 é que a natureza foi firmemente estabelecida como sendo uma onda eletromagnética de comprimento de onda muito menor que o da luz. E somente em 1920, com a dualidade onda-partícula, é que ficou estabelecido que a luz e os raios $\mathrm{X}$ apresentam caráter dual, e foi dado o nome de fóton à partícula associada à onda eletromagnética $[11,12]$.

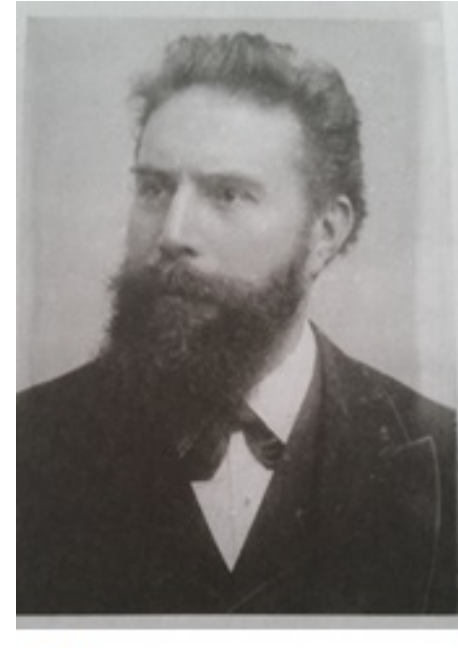

a)

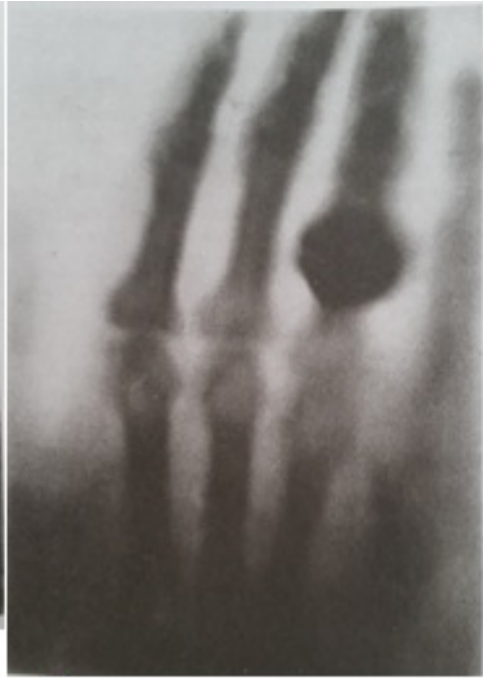

b)

Figura 3.1: a) Foto de Wihelm Conrad Röentgen. b)Diapositiva da radiográfia da mão da esposa de Röentgen. Anna Bertha Ludwing, tirada em 22/12/1895 [49].

Em 1896, o físico francês Antoine Henri Becquerel verificou que sais de Urânio emitiam radiações capazes de produzir sombras de objetos metálicos sobre chapas 
fotográficas. O fato que mais impressionou foi que os sais de urânio tinham uma radiação penetrante e que as emissões eram espontâneas. Trabalhando com sais deste elemento observou que as radiações eram proporcionais à concentração de urânio; verificou que as proporcionalidades permaneciam inalteradas através das variações: químicas, temperatura, de campo elétrico e magnético e até sobre pressão.

Entre os cientistas que mais se destacaram nas pesquisas sobre as radiações foram o casal Pierre e Marie Curie com investigações nas quais se preocuparam em verificar se outros elementos emitiam esses raios.

Em 1898, oficialmente anunciaram a descoberta de um elemento radioativo que deram o nome de Polônio (Po), em homenagem à pátria de Marie, que estava sob o domínio russo e não era reconhecida como nação. Além do Polônio, descobriram e separam uma outra substância mais radioativa ainda, que levou o nome de Radium $[11,12]$.

Logo após a descoberta dos raios $\mathrm{X}$ e da radioatividade, seguiu-se uma fase do uso desenfreado das radiações, que haviam se tornado solução para todos os males. Surgiram creme de beleza, chocolates, cigarros, águas e creme dentais. Os médicos ao tirarem radiografias para ver o formato de seus crânios por curiosidade, observaram que seus cabelos caíram hoje se sabe, como decorrência da falta de controle sobre a intensidade e da eneriga do feixe de raios X. Em janeiro de 1896, o primeiro tratamento radioterápico foi realizado na paciente Rose Lee com um câncer de mama avançado utilizando os tubos de raios $X$ [12]. 
O cientista Elihu Thomson fez os experimentos expondo deliberadamente o seu dedo mínimo da mão esquerda aos raios $X$, de meia a uma hora por dia, durante vários dias, em 1896. Como consequência, o dedo mínimo apresentou queimadura severa. O próprio Becquerel detectou queimadura na pele atrás do bolso da camisa onde levava um pequeno frasco contendo rádio, que havia recebido da Marie Curie, que ele levava para demonstração em suas conferências. Com isso, alguns médicos chegaram a eliminar mancha e pinta de nascença expondo-as aos raios X. Desta forma, iniciou-se a prática do que mais tarde seria chamado de braquiterapia $[11,12,13]$.

Aos poucos tornou-se evidente que a exposição à radiação provocava efeitos deletérios imediatos e tardios aos tecidos. Com isso, em 1902, houve uma preocupação em realizar medidas dosimétricas uma vez que no início da radioterapia a dose administrada no paciente era estabelecida pela tolerância da pele. Em 1906, Williams padronizou o tratamento, relacionando o tempo de exposição com a miliamperagem, através de uma tabela de intensidade de dose e uma medida de segurança relacionada com a mudança de cor que a radiação provocava em certas substâncias químicas $[4,12]$.

Em 1903, foi o primeiro sucesso da braquiterapia com dois pacientes com carcinoma basocelulares na face. E no ano de 1914, foram desenvolvidas as primeiras agulhas de sulfato de rádio puras com encapsulamento de aço ou platina e de gás radônio colocado em tubos de vidro implantados permanentemente no tumor. Com isso, novos trabalhos surgiram e as aplicações terapêuticas se 
ampliou o uso da braquiterapia no tratamento de câncer ginecológico $[4,12,13]$.

Em 1925, foi criada a primeira comissão internacional, denominada International Commission on Radiation Units and Measurements (ICRU), no Primeiro Congresso Internacional de Radiologia. Ela tinha por finalidade estabelecer grandezas e unidades de Física das Radiações, critérios de medida e efetuar sua divulgação. Isso possibilitaria a comparação entre medidas feitas em diferentes laboratórios, clínicas médicas e institutos de pesquisa, usando os mais variados equipamentos etc.

Em 1928, uma segunda comissão internacional, International Commission on Radiological Protection (ICRP), foi criada no segundo congresso internacional de radiologia. Essa comissão tem a incumbência de elaborar normas de proteção radiológica e estabelecer limites de exposição à radiação ionizante para indivíduos ocupacionalmente exposto (IOE). Ambas as comissões, ICRU e ICRP, reúnem-se regularmente ainda hoje e publicam normas novas e/ou atualizam outras $[4,12]$.

Em 1931, Quimby iniciou seus estudos sobre a distribuição de dose do rádio e preparou tabelas dosimétricas que tinham o rádio com apenas uma atividade. Esses estudos sobre a distribuição de dose do rádio deram origem às bases dos efeitos biológicos e a proteção dos efeitos indesejáveis da radiação. Neste mesmo ano, o termo braquiterapia foi proposto, pela primeira vez, por Forssel $[4,11,13]$.

Em 1934 o casal Irène Curie e seu esposo Frédéric Joliot produziram artificialmente, pela primeira vez, os isotopos radioativos fósforo e o nitrogênio, bombardeando, respectivamente, o alumínio e o boro com partículas alfas emiti- 
das por uma fonte de polônio. Já em 1935 foram descobertos novos elementos radioativos, tais como, ${ }^{192}$ Ir e ${ }^{137} \mathrm{Cs}[4,12]$.

A produção artificial de radioisótopos em grande quantidade só se tornou possível com o início do desenvolvimento de cíclotrons, no começo de 1930 . Essas máquinas forneciam partículas que, ao atingirem um alvo, induziriam reações nucleares.

No gerador eletrostático, de Van der Graaff, feixes de raios X eram gerados por elétrons acelerados em campos elétricos que produziam energias de até 5 MeV. Em março de 1937, com o gerador eletrostático foi tratado o primeiro paciente [7].

O ${ }^{226} \mathrm{Ra}$ foi largamente utilizado para controle local de tumores até a metade do século vinte [35]. Com o desenvolvimento dos reatores nucleares, em escala industrial, durante a segunda guerra mundial, tornou-se viável, a produção de fontes artificiais radioativas, a saber: ${ }^{60} \mathrm{Co},{ }^{182} \mathrm{Ta},{ }^{198} \mathrm{Au},{ }^{137} \mathrm{Cs},{ }^{192} \mathrm{Ir}$ e ${ }^{125} \mathrm{I}$, entre as mais utilizadas em braquiterapia [14].

Na década de 50, com o desenvolvimento dos aparelhos de telecobalto, surgiu a possibilidade de se tratar lesões profundas sem efeitos significativos sobre a pele [6]. Já na década de 70 , os implantes com agulhas de rádio foram substituídos pela técnica dos fios de irídio [15].

Na década de 80, surgiram novos radioisótopos e uma dosimetria mais refinada, com uma melhor distribuição de dose. A utilização dos computadores permitu a reprodução das imagens de tomografia e de ressonância magnética em 
formato digital, possibilitando uma maior exatidão nos procedimentos de braquiterapia mais precisos nos tecidos tumorais e neoplásicos, isto é, preservando mais os tecidos sadios [5].

\subsubsection{Radioterapia}

A radioterapia é uma especialidade médica que usa radiação ionizante para induzir a morte celular em um tecido tumoral no corpo do paciente. O princípio da radioterapia é que a dose seja a máxima possível na região do tumor, com o mínimo comprometimento dos tecidos sadios ao redor. Normalmente, as células tumorais são mais sensíveis à radiação do que as células sadias, porque se dividem com muita frequência. No entanto, com as doses necessárias para erradicar o tumor são muito elevadas (da ordem de 10 a 50 Gy), nem sempre é possível poupar adequadamente os tecidos adjacentes, e os pacientes muitas vezes têm reações teciduais.

A posição de dose máxima é tão profunda quanto maior for a energia dos fótons, por um efeito conhecido pela dosimetria como build up. Ele é resultante de três contribuições:

- Os fótons percorrem longos trajetos antes de interagir e, portanto, o feixe de fótons não é muito atenuado por pequenas espessuras de tecido.

- O elétron liberado por um fóton de alta energia recebe quase toda a energia do fóton e caminha na mesma direção do feixe original. 
- Os elétrons têm poder de freamento maior no final de sua trajetória, depositando muita energia na região próxima do fim do seu alcance. Dessa forma, na pele dos pacientes há pouco deposição de energia e à medida que a profundidade aumenta, a dose aumenta [12].

O procedimentos de radioterapia estão divididos em duas principais categorias: teleterapia e braquiterapia $[5,15]$.

\subsubsection{Teleterapia}

A teleterapia utiliza uma fonte de radiação posicionada no isocentro do aparelho que pode ser de 80 a $100 \mathrm{~cm}$ do paciente, cerca de 60 a $70 \%$ dos pacientes irão passar por tratamentos radioterápicos e desses pacientes cerca de 80 a $90 \%$ será tratado por teleterapia [3]. Os equipamentos mais utilizados na teleterapia são os aceleradores lineares, unidades de telecobaltoterpia e as máquinas de raios- $X$ (superficial e ortovoltagem). Dependendo da energia de radiação, pode-se dividir em:

- Terapia de Contato - tratamentos com raios X e opera com potenciais de 30 a $50 \mathrm{KVp}$, em média com corrente de $2 \mathrm{~mA}$, distância foco-superfície.

- Terapia de superfície - também são tratamentos com raios X para neoplasias de pele e opera com potenciais de 50 a $150 \mathrm{KVp}$, corrente no tubo entre 10 a $20 \mathrm{~mA}$ e distância foco-superfície entre 30 a $50 \mathrm{~cm}$.

- Terapia Profunda ou Ortovoltagem ou Radioterapia Convencional - utiliza 
em seus tratamentos raios $X$ para lesões de pele mais avançadas e opera com potenciais de $150 \mathrm{KVp}$ a $300 \mathrm{KVp}$, corrente no tubo entre 10 a 20 mA e distância foco-superfície entre 20 a $50 \mathrm{~cm}$.

- Megavoltagem são aqueles com energia de $1 \mathrm{MeV}$ ou mais MeV, por exemplo, os aceleradores lineares e as unidades de telecolbaltoterapia e tratamento de neoplasias viscerais.

Existe ainda a teleterapia com elétrons que é mais aplicada a tumores mais superficiais, principalmente quando as estruturas posteriores ao tumor são muito radiossensíveis, como por exemplo, é o caso de alguns tratamentos de câncer de mama, em que pulmões e coração devem ser poupados $[4,11,12]$.

\subsubsection{Braquiterapia}

O termo braquiterapia provém do grego onde brachys $=$ curto e terapia $=$ tratamento, ou seja, a braquiterapia (curieterapia) é um termo utilizado para descrever um tratamento de curta distância. Neste tipo de tratamento a fonte é colocada diretamente em contato com o tumor ou próximas do tumor $[2,3,4]$.

A braquiterapia emprega diversas fontes de raios gama e beta emissoras de meia-vida longas, para irradiações em que a fonte é introduzida e retirada da região da lesão, lá permanecendo por intervalos de tempo adequados, ou fontes de meia vida curtas nos implantes permanentes de fonte no paciente. Em alguns casos, a braquiterapia é recomendada como único tratamento e, em outros, é 
uma alternativa para complementar a irradiação externa. Alguns exemplos de radionuclídeos usados em braquiterapia, bem como suas propriedades físicas e sua forma de produção, são apresentados nas tabelas 3.1 e $3.2[12,13,16]$.

Tabela 3.1: Propriedades físicas dos radionuclídeos aplicados em braquiterapia e métodos de produção $[30,49]$.

\begin{tabular}{|c|c|c|c|}
\hline Radionuclídeos & Meia-vida & Método de produção & Forma da fonte \\
\hline \hline${ }^{192} \mathrm{Ir}$ & 73,8 dias & $\eta-\gamma$ & Fios e sementes \\
\hline${ }^{103} \mathrm{Pd}$ & 16,96 dias & $\eta-\gamma$ & Sementes \\
\hline${ }^{125} \boldsymbol{\gamma}$ & 60,1 dias & $\eta-\gamma$ & Sementes \\
\hline${ }^{90} \mathrm{Sr}$ & 28,90 anos & $\eta-\gamma$ & Placas \\
\hline
\end{tabular}

Tabela 3.2: Propriedades físicas dos radionuclídeos aplicados em braquiterapia $[30,49]$.

\begin{tabular}{|c|c|c|c|c|}
\hline Radionuclídeos & $\begin{array}{c}\text { Tipo de de- } \\
\text { sintregração }\end{array}$ & $\begin{array}{c}\text { Energia } \\
\text { máx. da } \\
\text { rad. } \beta \\
(\mathrm{MeV})\end{array}$ & $\begin{array}{c}\text { Energia } \\
\text { média da } \\
\text { rad. } \gamma \\
(\mathrm{MeV})\end{array}$ & $\begin{array}{c}\text { Energia } \\
\text { máx. rad. } \\
\gamma(\mathrm{MeV})\end{array}$ \\
\hline \hline${ }^{192} \mathrm{rr}$ & $\beta, \gamma$ & 0,67 & 0,380 & 1,06 \\
\hline${ }^{103} \mathrm{Pd}$ & E.C., Raios-X & - & 0,021 & 0,023 \\
\hline${ }^{125} \boldsymbol{}$ & $\begin{array}{c}\text { E.C Raios-X, } \\
\gamma\end{array}$ & - & 0,028 & 0,035 \\
\hline${ }^{90} \mathrm{Sr}$ & $\beta$ & 2,27 & - & - \\
\hline
\end{tabular}

Um radionuclídeo para ser usado em braquiterapia, deve ter as seguintes propriedades [13]:

- Apresentar uma emissão de raios gama adequada, ou seja, com energia suficientemente alta para evitar aumento da deposição de energia no osso por efeito fotoelétrico e para minimizar o espalhamento. Além disso, a 
energia deve ser apropriada para minimizar as necessidades de proteção radiológica;

- A meia-vida deve ser tal que a correção por decaimento durante o tratamento seja mínima;

- A emissão de partículas carregadas deve ser ausente ou efetivamente blindadas;

- Não deve produzir elementos gasosos em sua desintegração;

- Apresentar alta atividade específica;

- Estar disponível em forma insolúvel e não tóxica;

- O material não deve ser na forma de pó;

- É desejável que o material possa assumir várias formas e tamanhos, incluindo tubos rígidos, agulhas, esferas, sementes e fios flexíveis; e

- Não apresentar dano durante a esterilização.

Podem ser utilizadas no tratamento de tumores ginecológicos (colo, útero), da cabeça e pescoço, região perineal, sarcomas de partes moles, oftalmológico dentre outros.

A dose é liberada continuamente, durante um curto período de tempo (implantes temporários) ou sobre a vida média da fonte até um completo decaimento (implante permanente). 
A braquiterapia pode ser dividida em procedimentos de baixa taxa de dose (LDR), média taxa de dose (MDR) e alta taxa de dose (HDR). Segundo as normas do ICRU, a braquiterapia de baixa taxa de dose é aquela que libera de 0,4 a $2 \mathrm{~Gy} / \mathrm{h}$, a de média taxa de dose libera de $2 \mathrm{~Gy} / \mathrm{h}$ a $12 \mathrm{~Gy} / \mathrm{h}$ e a de alta taxa de dose libera mais que $12 \mathrm{~Gy} / \mathrm{h}$ [3].

A braquiterapia com alta taxa de dose com fontes gama de ${ }^{192}$ Ir tem pequenas dimensões ( $\sim 2 \mathrm{~mm}$ ), mas alta atividade (normalmente, $10 \mathrm{Ci}$ ou $370 \mathrm{GBq}$ ) e são empregadas com um sistema controlado por computador e planejado, de forma que a fonte é introduzida em catéteres ou aplicadores especiais e chega muito próximo de várias partes do tumor. No Brasil, a principal aplicação dessa técnica é o tratamento de tumores de colo de útero. Com essa modalidade, o tempo de irradiação para tratamento de tumor uterino diminuiu muito em relação ao que era utilizado anteriormente com a aplicação de tubos de ${ }^{60} \mathrm{Co}$ : baixou de 72 horas para dezenas de minutos de aplicação [12].

A vantagem da braquiterapia em relação à teleterapia é que a dose liberada no tumor é mais bem localizada. A desvantagem é que a braquiterapia só pode ser utilizada em casos onde o tumor é pequeno e bem localizado.

\subsubsection{Dosimetria}

Nesta seção apresenta-se uma breve fundamentação teórica sobre dosimetria, sistema dosimétrico e dosímetros. 


\subsubsection{Fundamento Teórico}

A dose absorvida de uma radiação é uma grandeza física definida como a relação entre a energia média, $d \bar{\varepsilon}$, depositada pela radiação ionizante em um volume elementar de massa, $d m$, e que serve de base para grandezas dosimétricas e de proteção radiológicas.

$$
D=\frac{d \bar{\varepsilon}}{d m}
$$

Essa grandeza vale para qualquer meio, para qualquer tipo de radiação e qualquer geometria de irradiação. A unidade de dose absorvida é J/kg, mas pelo Sistema Internacional de Medidas foi adotado o Gray (Gy), sendo 1Gy igual a $1 \mathrm{~J} / \mathrm{kg}$.

Em uma sessão de radioterapia, o tumor é, em geral, irradiado com dose absorvida de radiação de 2 Gy, e a dose total prescrita para o tratamento está em torno de 50 a 70 Gy. A dose letal, que mata $50 \%$ de seres humanos expostos no corpo todo à radiação em um intervalo de 30 dias é 4 Sv.

A taxa de dose é o quociente da dose absorvida, dD, no intervalo de tempo, $\mathrm{dt}$, e a sua medida é $[\mathrm{J} / \mathrm{kg} . \mathrm{s}][5,11]$.

$$
\dot{D}=\frac{d D}{d t}
$$




\subsubsection{Sistemas Dosimétricos}

Acho que seria importante definir o que é sistema dosimétrico antes existem alguns sistemas dosimétricos, por exemplo, Quimby, Paterson-Parker ou Manchester e outros todos com o objetivo de conseguir uma boa distribuição de dose. Eles se baseiam no uso de um conjunto de regras que levam em conta a atividade das fontes, a constante específica dos raios gama $(\Gamma)$ ou Razão Kerma$\operatorname{Ar}\left(\dot{K}_{a r}\right)$, a geometria das fontes e o método da aplicação, para que se obtenha uma distribuição de dose adequada através dos planos ou dos volumes a serem tratados.

As principais características dos sistemas dosimétricos destacados consistem:

- Sistema da Quimby (1932): É caracterizado por uma distribuição uniforme das fontes com mesma atividade. Este método não nos dá uma distribuição uniforme da dose que é bem maior no centro do plano (ou volume) do que na periferia. Quimby também posteriormente desenvolveu um sistema de dosagens para fontes lineares que são bem úteis para certos tipos de aplicação de aplicações braquiterápicas.

- Sistema de Paterson-Parker (1934): É caracterizado por uma distribuição não uniforme das fontes com o intuito de se conseguir uma dose com certa homogeneidade $( \pm 10 \%)$ em plano ou volume. O sistema, portanto, tem regras de distribuição do material radioativo.

O uso manual desses sistemas dosimétricos estão em desuso, devido à informa- 
tização dos centros de radioterapia com a aquisição cada vez maior de sistemas computadorizados para a leitura desses cálculos e distribuição da dose mais realistas [11].

\subsubsection{Cálculos Dosimétricos}

\section{1) TG - 43}

A Associação Americana de Físicos em Medicina (American Association of Physicists in Medicine - AAPM) publicou um protocolo que recomenda incluir um formalismo no cálculo de dose e os dados para definir os valores dos parâmetros dosimétricos para fontes de braquiterapia para aplicações intersticiais [17].

Este protocolo considera uma fonte cilindricamente simétrica, tal como mostra a figura 3.2. Para tais fontes, a distribuição da dose é bidimensional e pode ser descrito em termos de um sistema de coordenadas polares, com a sua origem no centro da fonte, pode ser escrito como:

$$
\dot{D}(r, \theta)=S_{k} \wedge \frac{G_{L}(r, \theta)}{G_{L}\left(r_{0}, \theta_{0}\right)} g_{L} F(r, \theta)
$$

Sendo $\dot{D}(r, \theta)$ a taxa de dose em função da distância $r$ e ângulo $\theta$ do centro da fonte; $S_{k}$ é a intensidade kerma-ar; $\Lambda$ é a constante de taxa de dose; $G_{L}(r, \theta)$ representa a função de geometria; $g_{L}$ é a função radial de dose e $F(r, \theta)$ quantifica a anisotropia ao redor da fonte. 


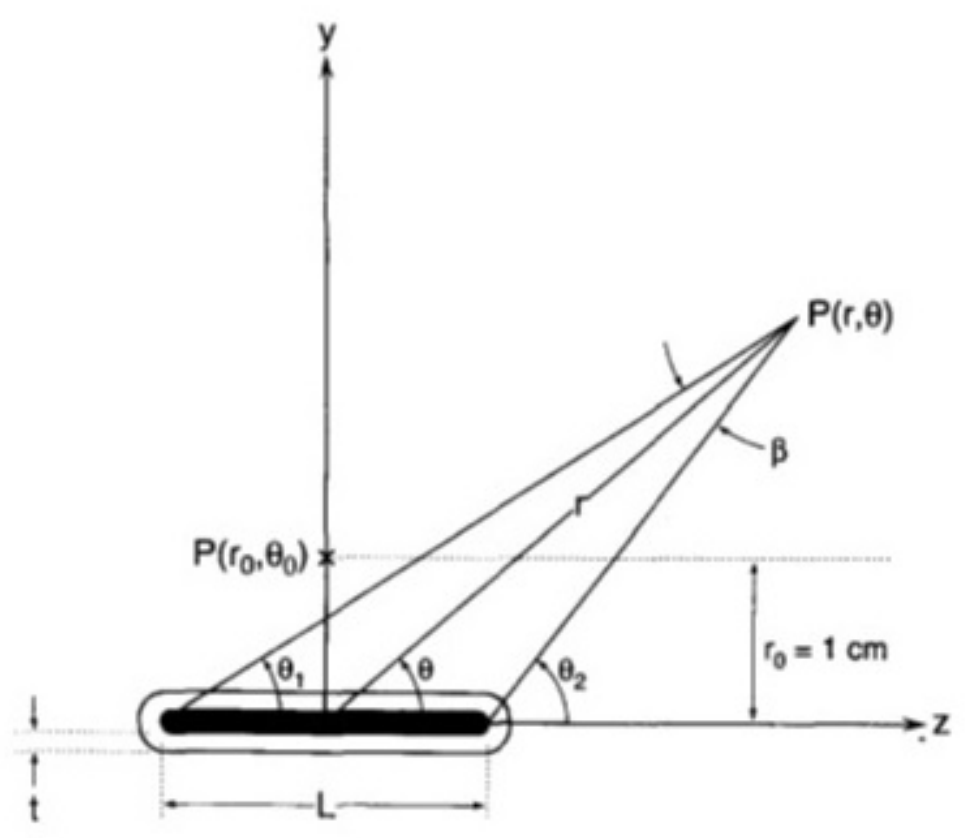

Figura 3.2: Ilustração da geometria assumida no formalismo do cálculo da dose. [57].

O ângulo $\beta$ é que subtendido pelo comprimento ativo no ponto $P(r, \theta)$ e o ponto de referência é representado por $P\left(r_{0}, \theta_{0}\right)$. A intensidade Kerma-ar $\left(S_{k}\right)$ é a medida da intensidade da fonte de braquiterapia, que é medida em termos da taxa de kerma no ar no ponto ao longo do eixo transversal da fonte no espaço livre. Essa medida é obtida por meio de câmaras ionização calibradas em laboratórios dosimétricos, para cada tipo de fonte utilizada [58]. A constante de taxa de dose expressa a razão de taxa de dose absorvida no ponto de referência $\left(r_{0}=1 \mathrm{~cm}\right.$ e $\left.\theta_{0}=90^{\circ}\right)$ com a intensidade kerma-ar $[17,18]$.

A função de geometria representa as variações de dose relativa devido apenas à distribuição espacial da atividade dentro da fonte, ignorando a absorção de 
fótons e dispersão na estrutura da fonte. O decréscimo da dose com o aumento da distância em relação ao centro da fonte, devido aos espalhamentos de fótons e atenuações, é quantificado pela função de dose radial. A anisotropia polar das fontes é estimada pela função de anisotropia. Estes cálculos são utilizados para uma fonte posicionada no centro de uma esfera com água. O subscrito $L$ inserido na função de geometria em função de dose radial denota a aproximação linear (2D) de uma fonte cilíndrica. Os três últimos termos da equação 3 são grandezas valores adimensionais $[17,18]$.

Algumas limitações ainda permanecem para representar melhor a prática clínica, dentre as quais, destacam-se:

- A taxa de dose descrita pelo TG-43 considera o espalhamento das radiações ionizantes em um meio homogêneo composto por um volume "infinito" de água, assim as heterogeneidades dos tecidos e as dimensões e formatos de cada paciente são desconsideradas;

- Os efeitos das atenuações entre múltiplas fontes também não são considerados, avaliando-se somente a sobreposição das doses absorvidas;

- Os aplicadores e demais acessórios não são considerados, porém alterações nas distribuições de dose ocorrem no meio analisado devido à presença destes materiais [18]. 


\section{2) TG - 186}

A abordagem do TG-43 tem sido amplamente adotada para o planejamento de dose em braquiterapia de alta taxa de dose (HDR) com fonte de ${ }^{192} / \mathrm{r}$. Usando uma tabela composta por valores obtidos através de um modelo geométrico para facilitar a interpolação linear para medidas de dose mais precisas sobre o formalismo do TG-43 que descreve a deposição de dose em torno de uma única fonte posicionada no centro de um objeto simulador esférico de água. Uma abordagem mais realista para calcular as doses no planejamento de braquiterapia é sobrepor as distribuições de dose pré-calculadas para fontes únicas em água de acordo com o padrão, ou seja, colocar a fonte na origem e levar em conta o tempo de permanência da fonte. Os dados de uma fonte única são derivados de modelo fonte das simulações específicas de Monte Carlo (MC) ou de medidas dosimétricas com TLD de acordo com as especificações descritas no TG-43 e são estritamente válidas apenas para um tamanho e formato de objeto simulador homogêneo [19].

Para unificar o formalismo e as limitações do TG-43 foi publicado o protocolo TG-186 que calcula a dose em braquiterapia utilizando algoritmos de cálculo de dose baseados em modelos (model-based dose calculation algorithms - MBDCAs), que tem como característica a distribuição de dose por todo o volume e a geometria do paciente, levando em conta a composição aproximada dos tecidos onde será realizado o tratamento do paciente [18]. Este algoritmo oferece a possibilidade de modelar o transporte de radiação em meios heterogêneos (por exemplo, tecido, aplicadores, interface tecido-ar), e não somente as geometrias 
em água. Com isso, tem-se uma reconstrução física mais precisa da distribuição de dose entregue ao paciente.

A aplicação clínica da correção da heterogeneidade é padrão de diversas modalidades. Essa transição foi possível graças ao surgimento do MBDCAs. Dos algoritmos existentes, três destacam-se para aplicações em braquiterapia: Método por convolução/superposição de cone colapsado (Collapsed-cone superposition/convolution method), Monte Carlo (MC) e Solução das equações de Boltzmann baseada em "grid" (Grid-Based Boltzman Equantion Solver - GBBES ou GBBS) $[18,19]$.

Estas recomendações foram revistas por membros da AAPM, em conjunto com a Sociedade Americana de Braquiterapia (American Brachytherapy Society - ABS), Grupo Australiano de Braquiterapia (Australasian Brachytherapy Group - ABG) e Grupo Europeu de Braquiterapia (Groupe Europén de Curiethéapie GEC) da Sociedade Européia para Radioterapia e Oncologia (ESTRO) [18].

\subsubsection{Dosímetros}

Para medidas de dose absorvida são utilizados materiais denominados dosímetros [6]. Um dosímetro é um equipamento que tem sensibilidade para detectar a presença de radiação, ou mesmo para quantificá-la. Eles são importantes também para a proteção radiológica, pois os tecidos que são irradiados não têm sensores de radiação ionizante. Normalmente junto com o dosímetro existe um equipamento de leitura associado ao dosímetro, o eletrômetro, formando o chamado sistema 
dosimétrico. Existem muitos tipos de dosímetros com diferentes características e capacidades adequadas para diferentes aplicações, diferentes sensibilidades e para diferentes radiações ionizantes $[1,11,12]$.

Os dosímetros apresentam algumas características importantes que devem ser conhecidas para que suas respostas sejam adequadamente interpretadas e para que sejam empregados corretamente. Dentre as quais, destacam-se:

- Eficiência - é um reflexo da interação da radiação com o volume sensível do detector (maior interação maior será a eficiência), muitas vezes, chamada de dependência energética.

- Exatidão - também conhecida como acurácia, avalia quando uma resposta do detector se aproxima do valor correto ou verdadeiro da grandeza que mede: o resultado é tanto mais exato quanto mais próximo estiver do valor verdadeiro. A exatidão só pode ser avaliada por comparação com um padrão.

- Sensibilidade - que pode ser dada pela menor quantidade possível de detecção (ou limite mínimo de detecção), ou pela razão entre a variação da resposta e a correspondente variação da quantidade que é medida: o dosímetro é mais sensível quanto maior for a sua resposta a um dado estímulo.

- Faixa dinâmica - representa o intervalo de valores da grandeza medida na qual ele produz uma resposta. É comum existir uma saturação do sinal medido, que deixa de variar ou passa a variar muito pouco (baixando muito 
a sensibilidade) a partir de um valor máximo. A ocorrência da saturação indica o limite superior da faixa dinâmica, ao passo que a quantidade mínima detectável define o limite inferior dessa faixa.

- Precisão - os valores obtidos com o dosímetros para uma mesma quantidade de radiação concordam entre si: quanto mais estreito for o intervalo de valores obtidos melhor será a precisão do detector. A repetibilidade relaciona-se com a precisão intrínseca do dosímetro. Já a reprodutibilidade relaciona-se com a precisão de todo o processo de medida.

- Resolução espacial - é a capacidade de distinguir dois sinais muito próximos (em energia, em posição, em tempo etc.).

- Linearidade de resposta - é uma relação linear entre o sinal do detector e a grandeza medida.

Na dosimetria de radiação existem inúmeros problemas relacionados com a medição de curvas de isodose e distribuições de doses profundidade em regiões de alto gradiente de feixes utilizando sistemas de medição convencionais, tais como câmaras de ionização, semicondutores, detectores termo luminescentes (TLDs), e filmes radiográficos. Câmaras de ionização e semicondutores não fornecem resolução espacial suficiente para muitas necessidades de planejamento de tratamento. Dosímetros de termoluminescência, mesmo com pequenas dimensões, são complicados e demorados quando a distribuições de dose em um ou duas dimensões são necessárias. Os dados dosimétricos não podem ser armazena- 
dos para fins de arquivo, usando procedimentos convencionais de leitura TLD. A avaliação de um feixe de fótons ionizantes é difícil usando filme radiográfico de haleto de prata, por causa de grandes diferenças de sensibilidade para energias de fótons na região de 10-200 keV, embora tenha uma resolução espacial relativamente alta oferece uma vantagem sobre a maioria dos outros sistemas de medida de radiação. A absorção e transferência das propriedades energéticas dos filmes radiográficos não coincidem com as dos tecidos biológicos. Os filmes radiográficos também têm as desvantagens de ser sensível à luz ambiente e exigindo processamento químico úmido [20].

Essas dificuldades levaram a uma busca por um dosímetro de radiação com alta resolução espacial, que não requer um desenvolvimento especial de procedimento e dá valores estáveis da dose absorvida com uma exatidão e precisão aceitáveis e uma facilidade de manipulação e análise de dados. Algumas destas características foram alcançadas com a introdução de dosímetros radiocrômico. Estes dosímetros, com alta resolução espacial e baixa variação da sensibilidade espectral são insensíveis à luz visível e oferecendo facilidade de manipulação e manuseio em luz ambiente [20].

\section{1) Filme}

O filme radiológico ou convencional consiste em uma emulsão fixada numa base de material plástico que contém em suspensão cristais de brometo de prata em material gelatinoso. 
Quando a radiação interage com esses cristais, eles ficam mais suscetíveis a mudanças químicas e formando uma imagem latente.

Após a exposição, quando o filme é então "revelado", os cristais expostos se reduzem a pequenos grãos de prata metálica, após isso, o filme é então "fixado" através de uma solução de tiossulfito de sódio que dissolve o brometo de prata e a gelatina de emulsão não expostos a radiação, não afetando a prata metálica. O filme é então lavado em água corrente para remover todos os resíduos químicos. No final, as áreas que foram expostas a radiação aparecem enegrecidas, proporcionalmente à quantidade de radiação recebida [11].

O filme radiocrômico é um novo tipo de filme utilizado em dosimetria para radioterapia. É aproximadamente tecido equivalente, devido a sua composição.

Quase transparente antes de ser irradiado o filme é composto de um material químico polimerizado, que adquire uma coloração esverdeada após a irradiação. O polímero absorve a radiação e pode ser medida com um escâner adequado. Esses filmes, apresentam alta resolução e podem ser utilizados para dosimetria de regiões de elevado gradiente de dose.

Diferente do filme convencional, que é muito sensível para ser usado como indicadores de dose em braquiterapia devido a sua saturação óptica, o filme radiocrômico é adequado em medições de alta taxa de dose.

Com relação aos filmes convencionais, o filme radiocrômico possui algumas vantagens como:

- Não necessidade de revelação do material com o uso de produtos químicos, 
agentes ópticos ou térmicos;

- Não utiliza câmaras escuras, pois tem baixa sensibilidade à luz visível;

- Resposta independente com a taxa de dose, boas características de dependência energética (exceto para Raios X com energias inferiores a $25 \mathrm{keV}$ ) e baixa dependência com relação às condições ambientais.

O filme radiocrômico Gafchromic EBT3 foi desenvolvido especialmente para atender as necessidades dosimétricas em técnicas de radioterapia. Suas principais características são:

- Alta resolução espacial; podem ser usados em altos gradientes de dose;

- Baixa dependência energética na faixa de keV a MeV;

- Uniformidade maior que $\pm 3 \%$;

- Resistência à temperatura acima de $70{ }^{\circ} \mathrm{C}$;

- Baixa sensibilidade a luz visível $[21,22]$.

\section{2) Câmara de Ionização}

Câmaras de lonização são basicamente constituídos de um capacitor preenchido com um gás (ou mistura). Entre os eletrodos do capacitor é aplicada uma diferença de potencial que tem o papel de dirigir as cargas liberadas no gás aos 
eletrodos de sinal contrário (Figura 3.3). As paredes externas desses detectores podem ser seletivas para algum tipo de radiação.

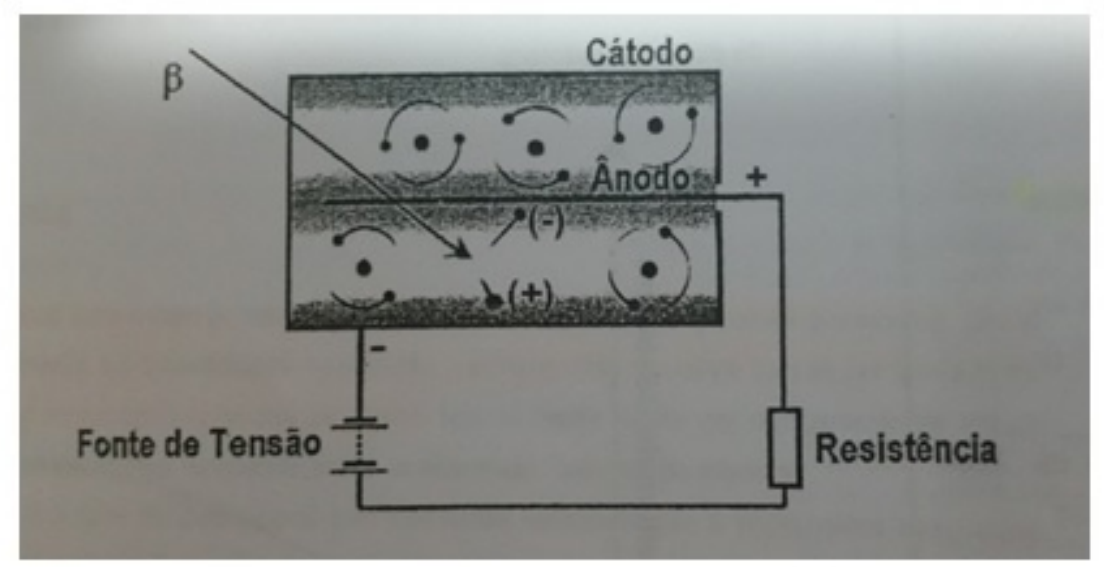

Figura 3.3: Desenho da Câmara de lonização [21].

A escolha da diferença de potencial é muito importante: ela deve ser suficiente para coletar todas as cargas produzidas antes de haver uma recombinação, mas não deve ser tão alta a ponto de romper a rigidez dielétrica do gás. Dentro desses limites, a diferença de potencial também define o regime de trabalho do detector $[11,12]$

Alguns exemplos de câmara de ionização:

- Câmara de lonização Padrão - Para medir exposição diretamente, precisa de um dispositivo que seja capaz de coletar cargas de um único sinal, produzidas por elétrons secundários criados num volume de ar de massa conhecida. 
- Câmara dedal - Na pratica, para medidas rotineiras, principalmente para medidas dosimétricas feitas em departamentos de radioterapia, a câmara de ionização padrão é de difícil uso e impraticáveis para certas finalidades.

- Câmara Condensadora - Para algumas finalidades é vantajoso ter a câmara separada do sistema de medida, isto é possível com um outro tipo de dosímetro integrador dosímetro Condensador, em que câmara e condensador formam uma peça única (por exemplo, caneta dosimétrica utilizada para monitoração pessoal).

- Câmara tipo Farmer - Uma câmara desenvolvida para o uso rotineiro de raios $\mathrm{X}$ ou gama, para todo $\mathrm{o}$ intervalo de energias usadas em radioterapia. É uma câmara estável e com ótima confiabilidade. Essa câmara, é conectada a um eletrômetro específico.

- Câmara de Placas Paralelas - Esta câmara consiste de duas placas, em que uma serve de janela de entrada com um eletrodo polarizador e a outra janela é um eletrodo coletor. Essas janelas são bem finas o que permite fazer medidas praticamente na superfície do meio e também pode-se desprezar a absorção pela janela.

- Câmara de Extrapolação - São utilizadas para medidas de cargas em meios onde a variação da quantidade de radiação é muito grande em distâncias (profundidades) muito pequenas. Nestas condições, necessita-se de uma câmara que permita a variação de seu volume sensível através da mudança 
da distância entre os eletrodos da câmara.

- Contador Geiger-Müller - A tensão aplicada nesse tipo de detector é tão elevada que a única ionização no gás provoca avalanche de ionização, obtendo-se um sinal, independentemente da energia que a radiação liberada no meio.

As características do contador Geiger Müller:

- Não distingue diferentes radiações incidentes.

- Tempo de resposta longo, que impede seu uso em radiologia diagnóstica.

- Não distingue as energias das radiações (qualquer radiação incidente conduz praticamente à mesma amplitude de pulso).

- Robustez e facilidade de uso torna util a para detectar qualquer tipo de radiação, desde que esta produza ionização em aréas contaminadas.

- Alta sensibilidade.

- As amplitudes de impulsos do Geiger Müller são maiores que as câmaras de ionização e, portanto, o equipamento eletrônico associado é bem mais simples $[11,12]$.

\section{3) Dosímetros Termoluminescentes}

Nestes dosímetros é aproveitado o fenômeno da termoluminescência. Materiais termoluminescentes tais como o fluoreto de Cálcio (CaF) ou o Fluoreto de Lítio 
(LiF) são materiais que emite luz visível quando são aquecidos, caso tenha sido submetidos a radiação. Os dosímetros termoluminescentes apresentam algumas vantagens:

- Sensibilidade de milésimos de cGy a milhares de cGy.

- Linearidade até mais de 5.000 cGy.

- Pequenas dimensões possibilitam dosimetrias intracavitárias.

- Quando o dosímetro está em um estado de excitação, este estado persiste indefinidamente, podendo a leitura ser feita a qualquer momento posterior à irradiação $[5,11]$.

\section{4) Dosímetros Semicondutores}

Semicondutores são cristais sólidos nos quais os elétrons fazem parte do processo de condução somente quando recebem incremento de energia. No caso dos dosímetros, transformam a ionização produzida em um cristal em pulso elétrico que depois é amplificado.

Algumas propriedades dos dosímetros semicondutores:

- Resposta linear;

- Resposta independentemente do tipo de radiação.

- Ótima resolução.

- Tamanho pequeno [11]. 


\section{5) Dosímetros Cintiladores}

Os dosímetros por cintilação avaliam a intensidade de luz emitida por um fóton produzidos no volume sensível e são excitados pela passagem da com radiação ionizante $[11,12]$. Nesse processo, há duas conversões de energia mantendo a proporcianlidade dos sinais de entrada e de saída, ou seja, o número de elétrons que sai do tubo fotomultiplicador é proporcional à energia da radiação que foi depositada no dectector.

Um tubo fotomultiplicador permite observar separadamente cada cintilação como pulso eletrico e amplificar propocionalmente esse número de pulsos dependendo da quantidade de interações que ocorram no detector [12].

\section{6) MOSFET}

Os MOSFET (Metal Oxide Semiconductor Field Effect Transistor) são pequenos dispositivos eletrônicos que, quando exposto a radiação ionizante, sofre alterações na sua estrutura que se vão traduzir numa variação da voltagem de threshold (voltagem acima da qual há condução de corrente através do dispositivo), proporcional à dose de radiação depositada na camada de óxido.

Os MOSFETs apresentam algumas vantagens:

- Pequenas dimensões.

- Recolha imediata de informação.

- Exatidão mesmo para doses pequenas aplicadas. 
- Capacidade para guardar a "história" de dose [23]. 


\section{Capítulo 4}

\section{Materiais e Métodos}

Neste trabalho foram usado filmes radiocrômicos Gafchromic EBT3, o scanner Epson Expression 10000 XL e os softwares ImageJ [14] e MATLAB [50] para a análise das imagens geradas dos filmes EBT3. Todas as leituras foram realizadas no ICESP (Instituto do Câncer do Estado de São Paulo) e os sistemas dosimétricos que foram utilizados pertencem a esse instituto. Já as fontes de braquiterapia, ${ }^{192}$ Ir, foram utilizadas as de propriedade do ICESP e do COI (Centro de Oncologias Integradas), e a fonte de ${ }^{60} \mathrm{Co}$ de propriedade do Hospital das Clínicas da Faculdade de Medicina de Botucatu. 


\subsection{Dados Experimentais}

\subsubsection{Materiais heterogêneos para fonte de ${ }^{192} \mathrm{Ir}$}

A medida de dose foi realizada em um objeto simulador composto por placas de PMMA com espessuras diferentes. Algumas dessas placas tem um furo central de $3 \mathrm{~cm}$ de diâmetro, onde um cilindro pode ser inserido. Todas as placas de disco têm um diâmetro de $3 \mathrm{~cm}$ e os cilindros heterogêneos, por exemplo osso, pulmão (exalado), com alturas de 1,8 e 4,3 cm. A figura 4.1 ilustra as placas e o cilindro de tecido equivalente utilizado no experimento e na Tabela 4.1 apresentam as densidades e as composições dos materiais utilizados.

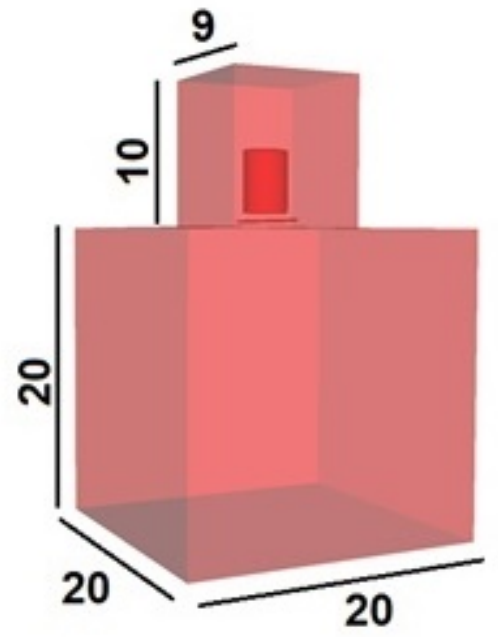

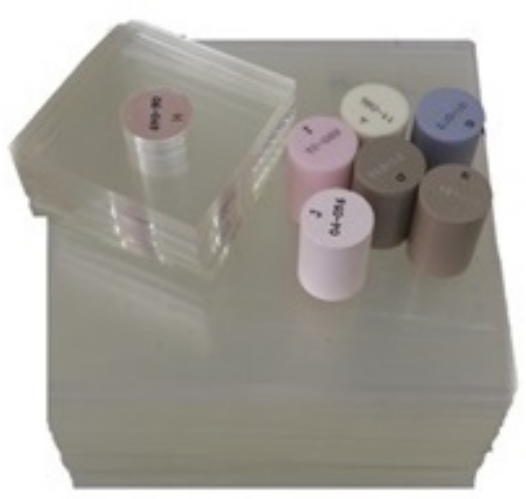

unidade: $\mathrm{cm}$

Figura 4.1: Placas de PMMA e os cilindros de tecido-equivalentes inseridos no centro com o catéter da fonte de ${ }^{192}$ Ir logo abaixo.

As medidas empregadas para cada uma das metodologias utilizaram placas de 
acrílico de $20 \times 20 \mathrm{~cm}^{2}$ de diferentes espessuras para garantir o retroespalhamento. O material heterogêneo foi inserido entre a fonte e os filmes radiocrômicos, os quais foram alinhados com o centro das placas e nas distâncias fixas de 2,0 e $4,5 \mathrm{~cm}$, a partir da fonte para os cilindros com alturas de 1,8 e $4,3 \mathrm{~cm}$, respectivamente. Logo acima dos filmes radiocrômicos foram posicionadas placas de PMMA e o conjunto (PMMA, filme e fonte) ficou uma altura de $10 \mathrm{~cm}$ para garantir o retroespalhamento. Para cada material descrito foram realizadas três irradiações, totalizando nove irradiações para altura de $4,3 \mathrm{~cm}$ e seis irradiações para $1,8 \mathrm{~cm}$ de altura. 
Tabela 4.1: Tabela 4.1 - Densidade e composição dos materiais tecidoequivalente.

\begin{tabular}{|c|c|c|}
\hline Material & Densidade $\mathrm{g} / \mathrm{cm}^{3}$ & Composição \% \\
\hline Osso 1 & 1,16 & $\begin{array}{c}56,3(\mathrm{C}), 22,7(\mathrm{O}) \\
7,0(\mathrm{H}), 2,0(\mathrm{~N}) \\
8,5(\mathrm{Ca}), 3,3(\mathrm{P}) \mathrm{e} \\
0,2(\mathrm{Cl})\end{array}$ \\
\hline Osso 2 & 1,66 & $\begin{array}{c}35,4(\mathrm{C}), 29,4(\mathrm{O}) \\
4,5(\mathrm{H}), 1,2(\mathrm{~N}) \\
\text { 19,9(Ca), 9,2(P), } \\
0,04(\mathrm{Cl}), 0,08(\mathrm{~S}) \mathrm{e} \\
0,33(\mathrm{Ba})\end{array}$ \\
\hline Osso 3 & 2,15 & $\begin{array}{c}17,9(\mathrm{C}), 35,6(\mathrm{O}) \\
2,3(\mathrm{H}), 0,7(\mathrm{~N}) \\
29,6(\mathrm{Ca}), 13,7(\mathrm{P}) \\
0,02(\mathrm{Cl}), 0,05(\mathrm{~S}) \mathrm{e} \\
0,20(\mathrm{Ba})\end{array}$ \\
\hline Pulmão (inalado) & 0,20 & $\begin{array}{c}67,5(\mathrm{C}), 18,6(\mathrm{O}) \\
8,8(\mathrm{H}), 3,5(\mathrm{~N}) \mathrm{e} \\
0,02(\mathrm{Cl})\end{array}$ \\
\hline Pulmão (exalado) & 0,51 & $\begin{array}{c}66,0(\mathrm{C}), 20,4(\mathrm{O}) \\
8,9(\mathrm{H}), 2,4(\mathrm{~N}) \\
1,7(\mathrm{Ca}) \text { e } 0,6(\mathrm{Cl})\end{array}$ \\
\hline Adiposo & 0,96 & $\begin{array}{c}71,3(\mathrm{C}), 16,4(\mathrm{O}) \\
10,0(\mathrm{H}), 1,8(\mathrm{~N}) \\
0,3(\mathrm{Ca}) \text { e } 0,2(\mathrm{Cl})\end{array}$ \\
\hline Mama & 0,99 & $\begin{array}{c}70,3(\mathrm{C}), 17,0(\mathrm{O}) \\
9,6(\mathrm{H}), 1,9(\mathrm{~N}) \\
0,9(\mathrm{Ca}) \text { e } 0,2(\mathrm{Cl})\end{array}$ \\
\hline Músculo & 1,06 & $\begin{array}{c}69,7(\mathrm{C}), 16,8(\mathrm{O}), \\
9,1(\mathrm{H}), 2,1(\mathrm{~N}), \\
2,2(\mathrm{Ca}) \text { e } 0,1(\mathrm{Cl})\end{array}$ \\
\hline
\end{tabular}




\subsubsection{Estudo comparativo entre a calibração de uma fonte de ${ }^{192}$ Ir e um Acelerador Linear}

Os filmes para calibração foram cortados em dimensões de $5 \times 5 \mathrm{~cm}^{2}$ e irradiados entre placas de PMMA, com uma fonte de ${ }^{192}$ Ir e um feixe de fótons de $6 \mathrm{MeV}$ em doses de 0,5 a 15 Gy. Cada uma das irradiações foi repetida três vezes.

As medidas efetuadas com a fonte de ${ }^{192}$ Ir utilizaram placas de água sólida de diferentes espessuras de $20 \times 20 \mathrm{~cm}^{2}$ sobre de $30 \times 30 \mathrm{~cm}^{2}$ para garantir o retroespalhamento, conforme ilustrado na Figura 4.2. Também colocado uma placa de acrílico de $20 \times 20 \mathrm{~cm}^{2}$ com um furo onde pode ser introduzido o catéter da fonte.

Já para as medidas efetuadas com o feixe de fótons de $6 \mathrm{MeV}$ utilizaram placas de água sólida de diferentes espessuras de $20 \times 20 \mathrm{~cm}^{2}$ sobre de $30 \times 30 \mathrm{~cm}^{2}$ para garantir o retroespalhamento.

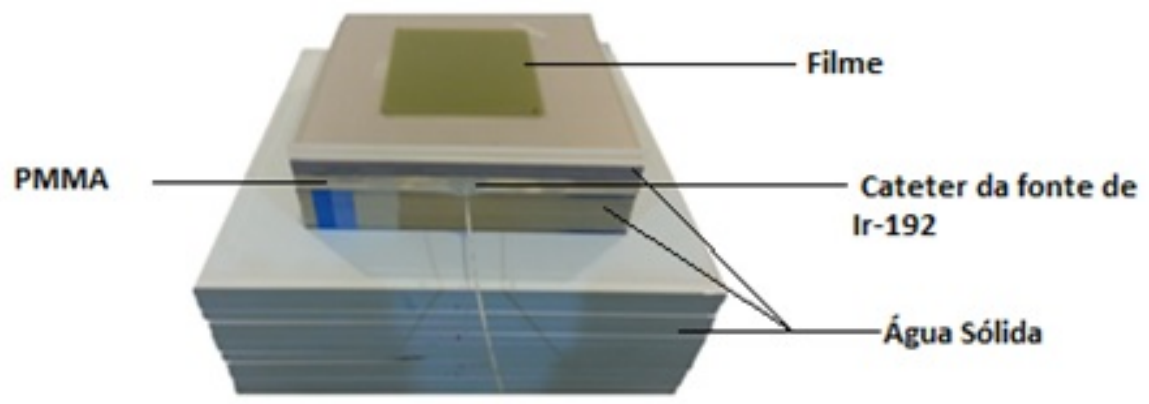

Figura 4.2: Placas de água sólidas e catéter da fonte de ${ }^{192}$ Ir inserido no centro da placa de PMMA. 


\subsubsection{Materiais heterogêneos para a fonte de ${ }^{60} \mathrm{Co}$}

Os filmes para calibração foram cortados em dimensões de $5 \times 5 \mathrm{~cm}^{2}$ e irradiados entre placas de PMMA, com doses de 0,25, 0,5, 1,0, 1,5, 2,5, 5, 10, 15, 30 e 50 Gy no feixe de ${ }^{60} \mathrm{Co}$ como mostra a figura 4.3. Cada uma das irradiações foi repetida três vezes.

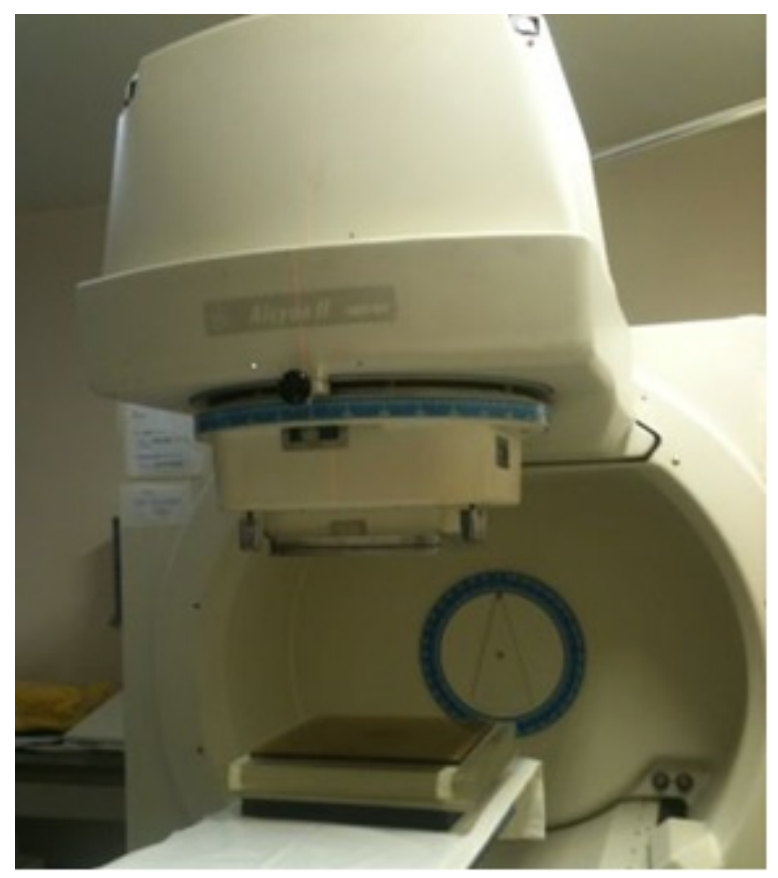

Figura 4.3: Unidade de telecobaltoterapia e as placas de acrílico com o filme que foram irradiados.

As medidas empregadas para cada uma das metodologias utilizaram placas de acrílico de $35 \times 35 \mathrm{~cm}^{2}$ de diferentes espessuras com altura de $10 \mathrm{~cm}$ para garantir o retroespalhamento. Os filmes foram colocados na altura de $5 \mathrm{~cm}$ das placas de acrílicos. Para as medidas de dose com material heterogêneo, foram utilizados cilindros simuladores de tecido, tais como apresentados na tabela 4.2 , com diâmetro de $3 \mathrm{~cm}$ e 4,3 cm de altura, inserida em placas com furos de 3 
$\mathrm{cm}$ de diâmetro. Os filmes radiocrômicos de $4 \times 4 \mathrm{~cm}^{2}$ foram posicionados, abaixo dos cilindros simuladores de tecido com uma dose prescrita (para água) de 2 Gy. Cada experimento foi repetido três vezes.

Tabela 4.2: Densidade e composição dos materiais tecido-equivalente.

\begin{tabular}{|c|c|c|}
\hline Material & Densidade $\mathrm{g} / \mathrm{cm}^{3}$ & Composição \% \\
\hline \hline Osso & 2,15 & $17,9(\mathrm{C}), 35,6(\mathrm{O})$, \\
& & $2,3(\mathrm{H}), 0,7(\mathrm{~N})$, \\
& & $29,6(\mathrm{Ca}), 13,7(\mathrm{P})$, \\
& & $0,02(\mathrm{Cl}), 0,05(\mathrm{~S}) \mathrm{e}$ \\
& & $0,20(\mathrm{Ba})$ \\
\hline Pulmão (inalado) & 0,20 & $67,5(\mathrm{C}), 18,6(\mathrm{O})$, \\
& & $8,8(\mathrm{H}), 3,5(\mathrm{~N}) \mathrm{e}$ \\
& & $0,02(\mathrm{Cl})$ \\
\hline Fígado & 1,08 & $69,4(\mathrm{C}), 16,4(\mathrm{O})$, \\
& & $9,0(\mathrm{H}), 2,1(\mathrm{~N})$, \\
& & $2,2(\mathrm{Ca})$ e $0,1(\mathrm{Cl})$ \\
\hline
\end{tabular}

\subsection{O filme GAFCHROMIC ${ }^{\mathrm{TM}}$ modelo EBT3}

O filme GAFCHROMICTM modelo EBT3 é um produto lançado no mercado internacional em 2012 e possui características de manufatura semelhantes aos modelos anteriores EBT e EBT2 cujo revestimento possui uma espessura de 28 $\mu \mathrm{m}$. Nestes dois modelos a camada ativa está contida entre 2 camadas de substrato de poliéster com espessuras de 175 e $50 \mu \mathrm{m}$, entretanto, no modelo EBT3 ambas as camadas possuem espessura de $125 \mu \mathrm{m}$, sendo que, este substrato é revestido com partículas de sílica (diâmetro menor que $10 \mu \mathrm{m}$ ) em sua superfície. A presença destas partículas é para evitar a formação de artefatos de imagens 
no contato do filme com a superfície do scanner (anéis de Newton) [24]. Como este modelo possui estrutura totalmente homogênea não há necessidade de se identificar a face do filme que estará em contato direto com a superfície do scanner.

A calibração do filme pode ser feita por meio da curva sensitométrica ou característica do filme, relacionando a densidade óptica (DO) do filme em função da dose, conforme a Figura 4.4, sendo que cada tipo de filme apresenta a sua curva característica.

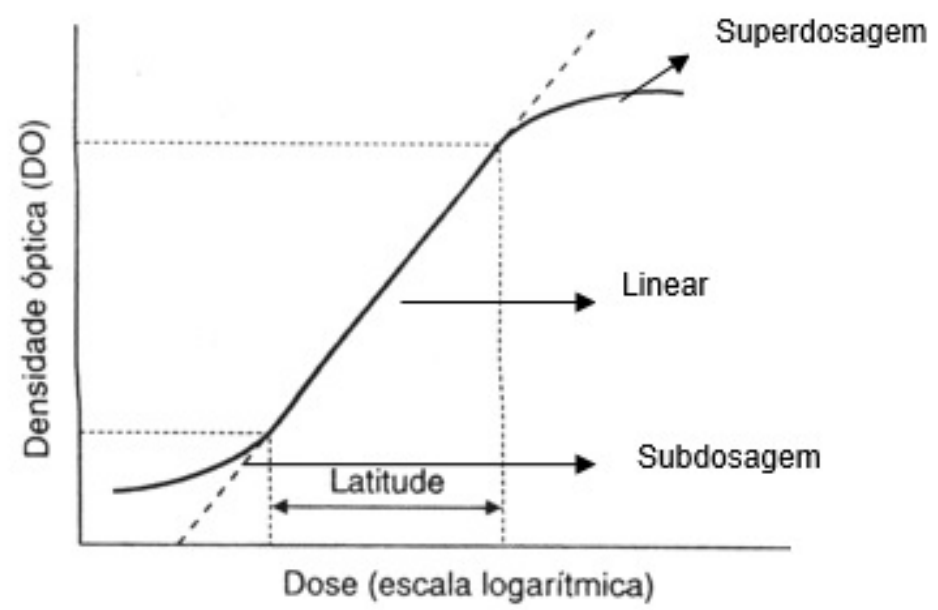

Figura 4.4: Curva sensitométrica. [21]

Na curva sensitométrica ou característica existem três regiões: a de subdosagem, a linear e a de superdosagem. A região de subdosagem é a região da curva que apresenta valores muito baixos de densidade, podendo ser considerado como ruído. Já na parte linear é conhecida como sendo a região de dose correta, onde os trabalhos com dosimetria são desenvolvidos. A última região da curva sensitométrica é a superdosagem, independentemente da quantidade de radiação que o 
filme está sendo exposto, a densidade óptica se manterá praticamente constante.

A densidade óptica é medida num aparelho denominado densitômetro óptico no qual é possível levantar a curva característica e assim determinar a dose. Outro meio de realizar a leitura do filme é digitalizá-los e analisá-lo através dos softwares ImageJ e Matlab.

\subsection{Fontes}

Nesta seção apresenta-se conceitos sobre as fontes utilizados no trabalho.

\subsection{1 ${ }^{192} \mathrm{Ir}$}

A fonte de radiação de alta taxa de dose, com sistema de pós-carga por controle

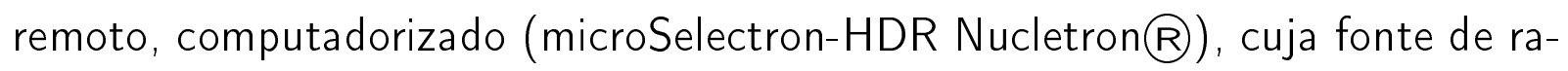
diação é uma semente de ${ }^{192} \mathrm{Ir}$, com atividade máxima de $10 \mathrm{Ci}$ no momento da instalação.

O elemento químico irídio ocorre na natureza, na forma mais usual, como metal em combinação com platina, ósmio, ouro e também, em minério de ferro. O irídio metálico é de coloração prateada e brilhante apresenta alta dureza e baixa ductilidade. A densidade é $22,65 \mathrm{~g} / \mathrm{cm}^{3}$ [25].

O ${ }^{192}$ Ir tem meia-vida de 73,81 dias, podendo assim ser usado facilmente para implantes temporários. Sua alta atividade o torna prático para fornecer até centenas de $\mathrm{GBq}$. O ${ }^{192}$ Ir decai para diversos estados excitados de ${ }^{192} \mathrm{Pt}$ através 
de decaimento $\beta^{-}(95 \%)$, e para ${ }^{192}$ Os via captura de elétrons (5\%), emitindo em média 2,3 raios gama por desintegração com uma faixa de energia entre 0,061 e 1,378 MeV e uma energia média de 0,355 MeV. Os raios $\beta^{-}$emitidos tem uma energia máxima de 0,675 MeV e uma energia média de 0,1807 MeV. O ${ }^{192}$ Ir é produzido a partir de alvos de ${ }^{191}$ Ir enriquecidos em um reator, criando fontes ${ }^{192}$ Ir de alta taxa de dose, com atividade excedendo 4,4 TBq.

As fontes ${ }^{192}$ Ir de média taxa de dose, usualmente, na forma de fios flexíveis de $0,3 \mathrm{~mm}$ e $0,5 \mathrm{~mm}$ de diâmetro e podem ser facilmente cortadas no comprimento requerido para cada aplicação (ver figura 4.5). Estes fios consistem de um núcleo de uma liga irídio-platina, são encapsuladas em uma capsula fina de titânio ou aço inoxidável e soldadas a laser. Os elétrons de decaimento beta são absorvidos pelo núcleo ou pelo revestimento.

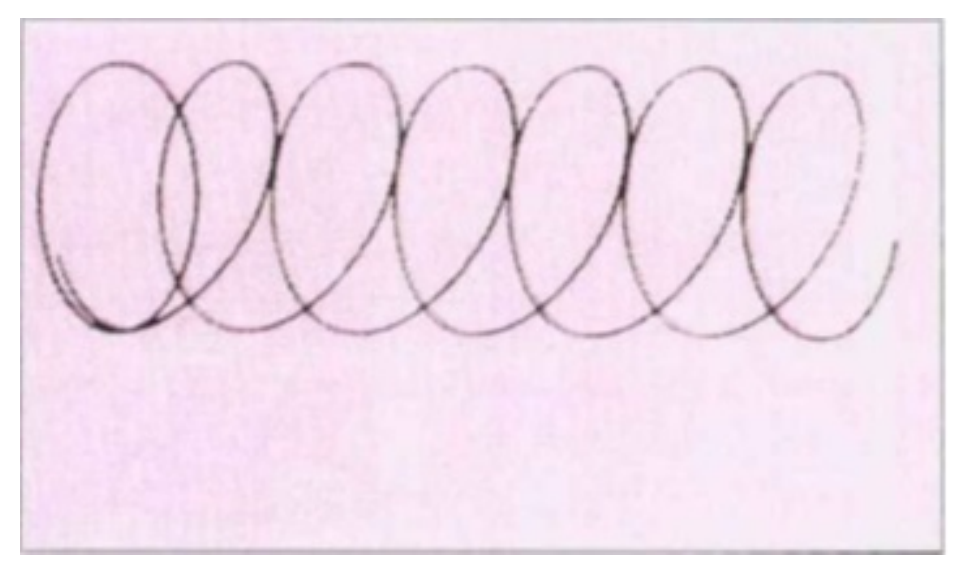

Figura 4.5: Desenho do fio irídio [30].

A platina é um metal de coloração cinza, brilhante, de baixa dureza e grande ductilidade. A densidade é de $21,45 \mathrm{~g} / \mathrm{cm}^{3}$ [25] 


\subsubsection{Unidades de telecobaltoterapia}

Até 1951, os únicos equipamentos existentes que usam radioisótopos como teleisotopoterapia eram as unidades de telerradium, que continham da 4 a $10 \mathrm{~g}$ de ${ }^{226} \mathrm{Ra}$. Esses equipamentos eram caríssimo e forneciam radiações gama de baixa intensidade, que tornavam esses aparelhos inacessíveis. Com o advento dos reatores nucleares, puderam ser produzidos radioisótopos de alta atividade para o uso médico, tais como o ${ }^{60} \mathrm{Co}[11]$.

As unidades de cobalto, assim como unidades de outros radionuclídeos, são basicamente um recipiente de chumbo ou outro material de alto número atômico e alta densidade, no interior do qual é colocada a fonte radioativa, e um mecanismo controlado à distância para deslocar a fonte para uma posição em frente a uma abertura que possibilite a saída do feixe de radiação [26].

$\mathrm{O}{ }^{60} \mathrm{Co}$ tem meia-vida física de 5,3 anos, emite radiações em cascata de 1,17 $\mathrm{MeV}$ e $1,33 \mathrm{MeV}$ e ${ }^{60} \mathrm{Co}$ decai, emitindo uma partícula $\beta^{-}\left(\mathrm{E}_{\max }=0,32 \mathrm{MeV}\right)$. A fonte de ${ }^{60} \mathrm{Co}$ utilizada consiste de cilindros envolvidos por duas cápsulas de aço inoxidável, vedadas com solda e com um diâmetro de 1 a $2 \mathrm{~cm}$. Esse invólucro serve para também para absorver as emissões da radiação $\beta$, portanto, os fótons gama são os principais constituintes do feixe útil. Além desses raios gama, o feixe é constituído por fótons de baixa energia e elétrons (produzidos pelas interações do feixe primário com os materiais do cabeçote da unidade) $[11,26]$.

As unidades de cobaltoterapia comportam fontes de $1,11 \times 10^{14}$ até $4,44 \times 10^{14}$ $\mathrm{Bq}[11]$ 


\subsubsection{Acelerador Linear}

Os aceleradores lineares clinac são equipamentos que obedecem a duas condições básicas para promoverem a aceleração de partículas. A primeira é que as partículas a serem aceleradas têm que ter carga elétrica. A segunda é que um campo elétrico na direção de aceleração das partículas deve ser provido.

Os aceleradores lineares, encontrados no Brasil, possuem um tubo acelerador onde elétrons, gerados em um "canhão de elétrons", são acelerados por ondas de radiofrequência até atingirem energias cinéticas da ordem de 4 a $25 \mathrm{MeV}$.

Para gerar o feixe de fótons, o feixe de elétrons acelerados é direcionado a um alvo para produção de raios-X. pela interação dos elétrons com o material do alvo, o feixe de fótons de Bremsstrahlung é gerado.

O espectro de fótons gerados nos aceleradores lineares apresenta uma distribuição contínua até a energia máxima de fótons, que é igual à energia cinética dos elétrons incidentes no alvo. Na realidade, apenas uma parcela bem pequena dos fótons terá energia igual à energia máxima possível [26] .

\subsection{Materiais simuladores de tecido humano}

Os experimentos planejados no presente trabalho foram realizados em objetos simuladores construídos especialmente para medidas de dose em braquiterapia composto de material homogêneo e heterogêneo por meio de simuladores de tecido humano. 
Medidas de dose foram realizados num objeto simulador constituído por placas de acrílico de diversas espessuras: 1, 2, 3, 5 e $10 \mathrm{~mm}$. Uma das placas é perfurada no sentido longitudinal para inserção da fonte de ${ }^{192} \mid r$, através de um catéter próprio utilizado para tratamento de pacientes. Filmes radiocrômicos foram colocados entre as placas de acrílico para as medidas de dose. Para simular um sistema heterogêneo, algumas placas de acrílico foram substituídas por placas simuladoras de tecido humano, tais como, osso, pulmão e tecido mole.

A figura 4.6a mostra alguns dos materiais simuladores que foram utilizados. $\mathrm{Na}$ figura $4.6 \mathrm{~b}$ mostra os principais componentes do objeto simulador que foi construído para os experimentos a serem realizados no presente trabalho.

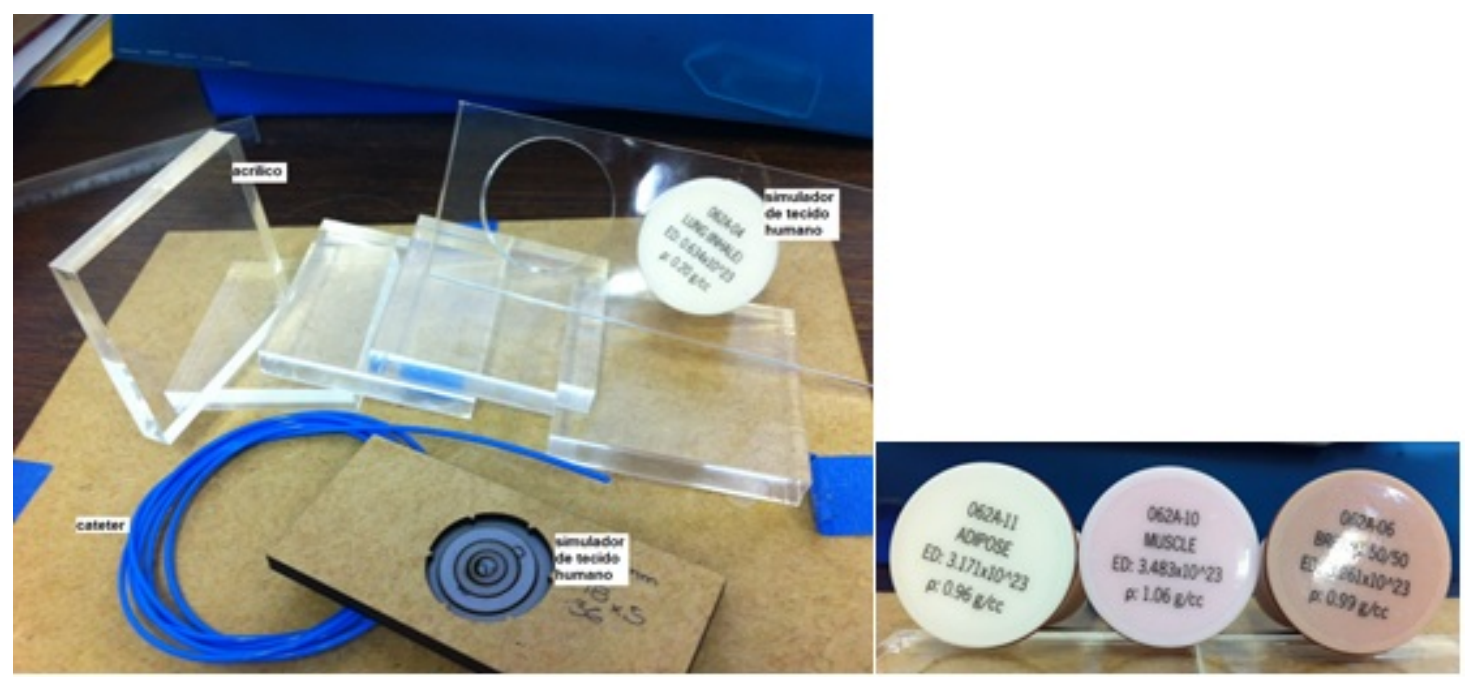

Figura 4.6: a) Componentes do objeto simulador para medidas de dose com filme EBT3 e b) materiais simuladores de tecido humano. 


\subsection{Scanner}

Para a digitalização dos filmes irradiados foi utilizado o modelo de scanner: Epson Expression 10000 XL. As imagens digitalizadas são coletados antes e 24 horas depois da exposição do filme e sem nenhum tratamento fotográfico. Essas imagens são positivas a cor (ou seja, canais de cor vermelho, verde e azul), resolução de 48 bits e 127 dpi. Após a digitalização dos EBT3, as análises foram feitas utilizando os softwares descritos nos itens a seguir [24].

\subsection{IMAGEJ}

O image J é um programa Java de domínio público para processamento e análise de imagem. Ele pode exibir, editar, analisar, processar, salvar e imprimir imagens 8 bits, 16 bits e 32 bits, além de ler diversos formatos de imagem, incluindo TIFF, GIF, JPEG, BMP, DICOM entre outros. Esse software é multithread, com isso pode-se realizar operações demoradas, como a leitura de um arquivo imagem, em paralelo com outras operações. Outras tarefas possíveis de serem realizadas com este programa são: medição de distância e ângulos, criação de histogramas de densidade e gráficos de perfis de linha, transformações geométricas, calibração espacial, etc [27].

Após a digitalização dos filmes, o ImageJ permite selecionar uma região de pixels e através da criação de histogramas de densidade e gráficos de perfis de linha da região. Uma vez identificada a região de pixels de maior valor, com esses 
dados é possível encontrar a densidade óptica líquida. Estes dados por sua vez foram colocados no software Excel, onde foi realizada toda a análise pelo método da Linearização.

\subsection{MATLAB}

O MATLAB pode ser definido como software cujo elemento básico de trabalho são matrizes (o nome MATLAB vem do inglês "MATrix LABoratory") podendo ser facilmente expresso em notação matemáticas e rapidamente solucionados por meio de cálculos computacionais eficientes e confiáveis.

Aplicações típicas deste software incluem:

- Matemática e computação;

- Desenvolvimento de algoritmos;

- Aquisição de resultados;

- Modelamento, simulação e prototipação;

- Desenvolvimento de aplicativos.

Os recursos do MATLAB podem ser divididos em cinco grandes categorias:

1. Ambiente de desenvolvimento: consiste no ambiente interativo do programa propriamente dito, ou seja, o MATLAB (["Command Window"], 
outras janelas e menus), no qual o usuário pode facilmente elaborar instruções e comandos para testar ideias e verificar resultados.

2. Biblioteca de funções matemáticas do MATLAB: núcleo do MATLAB, composto por mais de 1000 funções, desde as mais elementares, como soma e subtração, até as mais sofisticadas, como inversa de matriz, transformadas de Fourier, "solvers" de equação diferencial ordinária.

3. Linguagem de programação MATLAB: linguagem de alto nível, cujas estrutura de dados principal são matrizes que não precisam ser previamente dimensionadas. Além disso, a linguagem é 'orientada por objetos', o que torna sua programação mais simples e eficiente do que a programação tradicional.

4. Recursos gráficos do MATLAB: biblioteca de funções gráficas, que disponibiliza recursos poderoso e flexíveis para a criação de gráficos para a visualização de resultados.

5. MATLAB Application Program Interface (API): biblioteca que permite integrar o programa com funções desenvolvidas em C e Fortran [28].

Com isso, o programa desenvolvido permite após a digitalização dos filmes selecionar uma região de pixels e apresenta diversas funções onde foi realizada toda a análise pelo do método dos três canais. Fornecendo assim, obtenção das constantes das curvas de calibração e a dose após a correção da perturbação. 


\subsection{Linearizações}

As medidas de distribuição de dose são realizadas utilizando dosímetros que tem reposta linear, por exemplo câmara de ionização. Os valores de dose relativa são apenas a razão entre a leitura do dosímetro em um dado ponto e a leitura normalizada nesse mesmo ponto.

No passado o filme radiográfico era usado para medir o achatamento e a simetria dos feixes de fótons, por ter uma resposta linear semelhante à câmara de ionização em um intervalo relativamente estreito de distribuição de dose no filme. Era uma prática comum ter apenas uma razão de densidades ópticas líquidas medidas e declará-las como doses relativas, tendo em mente que as doses reais estão dentro da faixa de linearidade, anteriormente estabelecida, para um determinado modelo de filme radiográfico.

A fim de medir a distribuição de dose em relação ao filme radiocrômico, é necessário primeiro medir a dose em termos absolutos, seguindo um protocolo de dosimetria previamente estabelecido, e em seguida, converter as doses absolutas medidas em doses relativas [29].

Na figura 4.8 é mostrado a reconstrução de uma curva dosimétrica para filmes radiocrômicos. Os valores $D_{1}$ e $D_{2}$ correspondem aos valores densidade óptica líquida obtidos de netDO $O_{1}$ e net $D O_{2}$ usando a curva de calibração do filme radiocrômico. Já o valor $D_{1}^{\prime}$ corresponde ao valor de net $D O_{1}$ se a curva resposta fosse linear. 


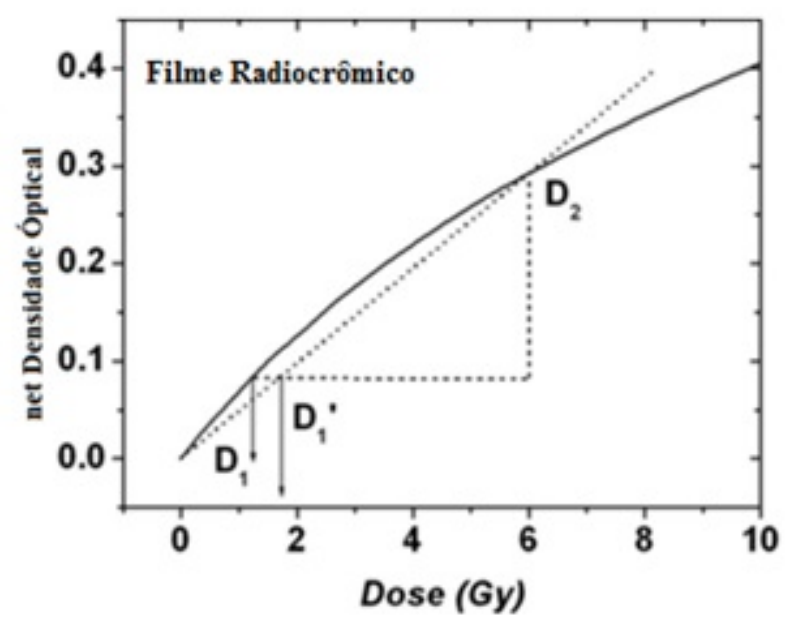

Figura 4.7: Curva sensitométrica do filme radiocrômico. A linha pontilhada simula uma reposta linear [29].

A proposta é linearizar a resposta não linear do filme radiocrômico baseado na curva sensitométrica de um sistema dosimétrico de referência. Logo, a forma da função que lineariza a dose-resposta pode ser expressa pela seguinte equação $[29,30]:$

$$
D=a \cdot(-1) \frac{n e t D O^{\left(\frac{2}{3}\right)}}{\ln (\operatorname{net} D O)}=a . \varsigma
$$

Onde $D$ é a dose, a é o coeficiente angular e net $D O$ é a densidade óptica líquida. A equação acima mostra que o método é independente do modelo de filme e do tipo de scanner.

A densidade óptica líquida foi obtida a partir do cálculo dos pixels das imagens digitalizadas dos filmes antes e após a irradiação. A relação dos valores da densidade óptica e de pixels, $V P$, é dada por $[29,30]$ : 


$$
n e t D O=D O_{\text {exp }}-D O_{n e x p}=\log \left(\frac{V P_{\text {nexp }}}{V P_{\text {exp }}}\right)
$$

Onde $\mathrm{DO}_{\exp }$ e $\mathrm{DO}_{\text {nexp }}$ são as densidades ópticas expostas e não expostas e $V P_{\exp }$ e $V P_{\text {nexp }}$ são os valores dos pixels exposto e não exposto.

A curva de calibração é criada a partir de doses conhecidas que foram ajustadas para determinação dos valores de a. Para cada curva criada é possível obter o valor do $R^{2}$, no caso, iguais ou superiores a 0,999 .

Com isso, é possível construir uma equação que linearize a curva resposta do filme e assim encontrar a dose para cada canal de cor. Cada canal de cor tem uma faixa de dose correspondente, ou seja, o canal vermelho é para doses até de 1 Gy, o canal verde de dose acima de 1 até 10 Gy e o canal azul de dose de 10 até 50 Gy $[29,30]$.

\subsection{Multicanais}

Vários pesquisadores têm apontado para o desafio do uso do filme radiocrômico: Uso de um único canal, aumento dos valores de densidade devido ao artefatos e variações na espessura $[4,31]$.

O método dos multicanais permite que se separe as imagens digitalizadas em duas partes: parte independente da dose (espessura e artefatos na digitalização, por exemplo, ruído e efeitos das partículas de poeira) e a parte dependente da dose (mapa da dose). Com isso, as informações dos canais de cor relacionados 
com a dose (canais vermelho, verde e azul) tem a vantagem de levar em conta qualquer perturbação, $\Delta$, que possa estar presente no filme radiocrômico.

Segundo o fabricante existem várias funções de ajuste para os dados de calibração, incluindo funções polinomiais e exponenciais, mas a função recomendada é uma classe de funções conhecida como funções racionais. Em termos de densidade óptica $\mathrm{DO}_{\mathrm{C}}$, dose $\mathrm{D}$, o comprimento de onda $\mathrm{C}(\mathrm{D})$ e as constantes $\mathrm{a}_{\mathrm{C}}, \mathrm{b}_{\mathrm{C}}$ e c (são definidas a partir de valores de dose conhecidos). Essa função assumiu a forma [31]:

$$
D O_{C}=-\log \left(\frac{\left(a_{C}+b_{C} D\right)}{\left(c_{C}+D\right)}\right)
$$

As vantagens dessa função:

- Simples para inverter e determinar a densidade em função da dose;

- A densidade do filme deve aumentar com o aumento da exposição e assume valores quase constantes. As funções polinomiais não correspondem com os dados fora do intervalo dos filmes de dados e mesmo dentre do intervalo pode oscilar entre os pontos.

- As funções racionais exigem menos pontos de calibração, poupando tempo e filme. Para um intervalo de dose de 0 a 320 cGy, por exemplo, são necessários apenas de 6 a 8 pontos e com isso determinar as três constantes de calibração para cada canal de cor.

O método será divido em duas partes para facilitar a compreensão. 
- Método de um único canal

Antes da separação das duas partes digitalizadas é necessário encontrar os valores do coeficiente de calibração. Para isso a densidade óptica digitalizada para um único canal é definida como $[30,31]$ :

$$
D O_{C}=-\log (C)
$$

Sendo C o canal de cor (ou seja, vermelho, verde ou azul) que é normalizado entre $[0,1]$ pela equação:

$$
C(D)=\left(\frac{V P_{C}}{65535}\right)
$$

Sendo VP o valor da região de pixels e em acordo com a Lei de Beer-Lambert, temos que [31]:

$$
D O_{C}=D_{C}^{D}(D) \tau
$$

Sendo $D O_{C}$ o termo que dependente somente da dose $\mathrm{D}$ e $\tau$ é a variação na espessura (adimensional). Essa equação tem que cumprir os casos limites a seguir:

$$
\lim _{\tau \rightarrow 0} C(D)=1
$$

ou seja, o filme é totalmente transparente para a espessura zero e 


$$
\lim _{\tau \rightarrow \infty} C(D)=0
$$

ou seja, é totalmente opaco para espessuras infinitas.

Considerando uma região homogeneamente exposta do filme, segue a densidade óptica média, $D \bar{O}_{C}(D)$ :

$$
\overline{D O_{C}}=\frac{1}{N} \sum_{i, j} D O_{C}^{D}(D) \tau=D O_{C}^{D}(D) \bar{\tau}
$$

Onde $\bar{\tau}$ é a espessura média do filme

$$
\bar{\tau}=\frac{1}{N} \sum_{i, j} \tau
$$

e $\mathrm{N}$ é o número de pixels $(i, j)$ na região.

Assumindo que $\tau / \bar{\tau}=1$ isto é a camada ativa é perfeitamente uniforme, torna-se:

$$
\overline{D O_{C}}=-\log \left(\frac{\left(a_{C}+b_{C} D\right)}{\left(c_{C}+D\right)}\right)
$$

Sendo $\overline{D O}{ }_{C}$ o valor da densidade óptica de calibração para o canal de cor.

- Método dos três canais

A partir das equações é possível calcular os valores dos coeficientes de calibração. Com isso, pode-se separar a imagem digitalizada em duas de partes para cada canal de cor $\mathrm{C}$ com a densidade óptica dada por [30,31]: 


$$
D O_{C}=D O_{C}^{D}(D) \cdot \triangle
$$

Sendo que, $D O_{C}$ é a densidade óptica medida, $D O_{C}^{D}(D)$ é a componente da densidade óptica que não depende da perturbação, mas apenas da dose $D$ e $\triangle$ a perturbação. É importante que $D \bar{O}_{C}$ tenha uma região de exposição que seja suficiente grande, para assegurar que as condições de calibração para a perturbação média seja satisfeita, caso contrário $D \bar{O}_{C}$ irá desenvolver um desvio sistemático [31].

$$
\bar{\triangle}=1
$$

Calculando a média de $D O_{C}$, numa região homogênea tem-se:

$$
D \bar{O}_{C}=D O_{C}^{D} \cdot \bar{\triangle}
$$

Sendo $\bar{\triangle}=\frac{1}{N} \sum_{i, j} \triangle$ e $N$ é o número de pixels $(i, j)$ na região. A partir de uma curva de calibração conhecida para cada canal de cor, C, a densidade óptica $\left\{\overline{D O}\left(D_{i}\right) ; D_{i}\right\}$ passa a ser conhecida para cada dose $\mathrm{Di}$, logo, a dose é obtida por:

$$
D=[\overline{D O}]^{-1}\left(D O_{C} \cdot \frac{\triangle}{\bar{\triangle}}\right)
$$

No entanto, considerando que a dose é independente do canal de cor $\mathrm{C}$, e 
sabendo que ele carrega o termo de perturbação $\triangle, L(\triangle)$, para minimizar as diferenças entre os valores de dose obtidos a partir dos canais individuais de cor vermelho, verde e azul, utiliza-se as seguintes equações [31]:

$$
\begin{gathered}
L(\triangle)=\sum_{C_{i} \neq C_{j}}\left(D_{C_{i}}-D_{C_{j}}\right)^{2} \rightarrow \text { min. } \triangle \\
\frac{d L(\triangle)}{d \triangle}=0
\end{gathered}
$$

A equação permite ao método eliminar as diferenças provenientes de variações da espessura da camada ativa do filme, entre outros fatores não relacionados à energia depositada $[30,31]$.

\subsection{Método de Monte Carlo}

O método de Monte Carlo consiste em simular um problema matemático de forma estocástica. Sua aplicação se estende a qualquer problema descrito em termos de uma função densidade probabilidade através de um gerador de números aleatórios usados para amostrar todos os eventos possíveis do problema em questão. As respostas estimadas destas amostragens aleatórias são armazenadas de forma apropriada com o intuito de se produzir o resultado final desejado. $\mathrm{O}$ uso do método de Monte Carlo aplicado ao transporte de radiação está em estimar determinadas quantidades de interesse. Esta estimativa se dá pela análise do comportamento de um número grande de eventos individuais, isto é, o método de 
Monte Carlo lida com um evento de cada vez, de modo que processos complexos sejam simulados a partir da soma de processos simples. O conjunto de eventos que ocorre com uma determinada partícula, desde o momento em que ela é emitida pela fonte até o momento em que ela é absorvida ou escapa do sistema é denominado trajetória da partícula [32].

\subsubsection{Teoria do Modelo}

Amostragem A característica essencial do método de MC é o uso de técnicas de amostragem para se chegar à solução do problema físico. Essas técnicas de amostragem utiliza a geração de números aleatórios para os processos de interação da radiação com a matéria para descrever os feixes produzidos por diversas fontes de radiação, utilizando funções de densidade de probabilidade conhecidas $[32,33]$.

Com isso, $f\left(x_{0}\right) d x$ descreve a probabilidade de ocorrer um valor $x_{0}$ tal que $x<x_{0}<x+d x$. Sendo a função de densidade de probabilidade (fdp) normalizada com $x \epsilon[a, b]$ que representa um dado sistema unidimensional é dada por $f(x)$, tal que:

$$
\int_{a}^{b} f(x) d x
$$

Associando às fdp's com a função de densidade cumulativa $(\mathrm{fdc})$ no caso unidimensional temos: 


$$
\int_{a}^{x} f\left(x^{\prime}\right) d x^{\prime}
$$

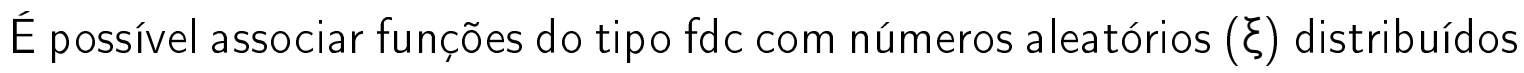
uniformemente no intervalo de $[0,1]$, tem-se:

$$
\xi=F(x)
$$

Invertendo a função é possível amostrar as funções utilizando um gerador de números aleatórios de forma que os valores de probabilidade tendam ao valor da probabilidade real, como descrito pela lei dos grandes números, desta forma, tem-se:

$$
x=F^{-1}(\xi)
$$

\subsubsection{O código MCNP5}

O código MCNP5 [34] é um software que utiliza o método de Monte Carlo que pode ser descrito como um método estatístico, onde se utiliza uma sequência de números aleatórios para a realização de uma simulação para o transporte de partículas, como nêutrons (com energia de $10^{-11} \mathrm{MeV}$ a $20 \mathrm{MeV}$ ), fótons e elétrons (ambos com energias de $1 \mathrm{keV}$ a $100 \mathrm{MeV}$ ).

Para se fazer uma simulação é necessário criar um arquivo de entrada (input), que permite especificar todas as informações da geometria até as especificações 
da fonte, materiais e tally (que fornece o tipo de resposta que se deseja obter dos cálculos).

A estrutura geral de um arquivo de entrada com os dados de entrada é: Bloco de células: Utiliza as combinações de formas geométricas determinadas pelos modelos experimentais já citados e descritas no item subsequente (Bloco de Superfície). A combinação das regiões é realizada, através de intersecções, uniões etc. As densidades que compõe a geometria do problema, também são definidos nestas células.

Bloco de Superfície: A definição das superfícies geométricas do experimento simulado é feita utilizando caracteres mnemônicos que indicam o tipo de superfície e os coeficientes da equação da superfície selecionada.

Blocos de Dados: Dados de entrada onde se define os parâmetros da física do problema. Esta seção é dividida em vários subitens, a saber:

- "MODE Cards": Definição do tipo de transporte de radiação (por exemplo, fótons).

- "IMP Cards": Parâmetros que permitem diferenciar as regiões de maior importância da história da partícula. Essas regiões são representadas por: menor importância ( 0 - as partículas são eliminadas) e maior importância (pode ser maior que 1).

- "SOURCE Cards": Dados que definem os parâmetros das fontes utilizadas. Local onde são definidos: posição da fonte, tipo de partícula, energia e 
entre outras que caracteriza uma fonte.

- Os materiais de cada célula são descritos por sua composição logo após os parâmetros da fonte, podendo ser expressa em fração atômica ou de massa.

- "TALLY Cards": Opção de escolha da grandeza de interesse a ser obtida dos resultados.

Define-se o tipo de resposta que se deseja. Estas informações são obtidas através de um ou mais cartões de tallies. Por exemplo, o tally F8 é uma contagem de pulsos energéticos, ou seja, passa a ser a estimativa da intensidade de pulsos produzidos pela interação da radiação, de forma similar aos detectores reais. Este se dá pela diferença entre a energia das partículas quando elas entram no volume e quando elas saem.

O tally F4 é a estimativa do fluxo médio de partículas ("Track length" caminho médio percorrido pela partícula na célula) em uma determinada célula. O resultado ainda pode ser subdivido em função da energia das partículas.

O tally F6 é a estimativa da energia média depositada numa célula, ou seja, consiste em um tally F4 (de fluxo), multiplicado por uma função dependente da energia e pela seção de choque, considerando que toda a energia transferida é depositada localmente.

Quando se adiciona o $\left(^{*}\right)$ ao tally, o resultado é multiplicado pela energia. Por exemplo, no caso do tally *F8 a contagem de pulsos é convertida em deposição 
energética. O cálculo se dá pela diferença de energia de uma partícula, ao entrar e sair da célula de interesse, armazenando os resultados em diferentes intervalos, de acordo com os diferentes resultados da energia depositada. Esses resultados armazenados são divididos pelo peso das partículas (peso coletivo das partículas do tally F8) no final de cada história.

Todos os resultados acompanhados por um segundo número, que é a estimativa do erro relativo, $\mathrm{R}$, definido como a razão da estimativa do desvio padrão da média $\left(\bar{S}_{x}\right)$ pela média estimada de todas as histórias $(\bar{x})$, dado pela equação $[5,33,34,35]:$

$$
R=\frac{\bar{S}_{x}}{\bar{x}}
$$

\subsubsection{Simulação do Experimento}

Foram realizadas duas simulações, sendo uma para cada tipo de fonte. As fontes foram inseridas em objetos simuladores, que são compostos por cilindros de material heterogêneo tendo diâmetro de $3 \mathrm{~cm}$ e placas de acrílico de espessuras variando de $0,1 \mathrm{a} 1 \mathrm{~cm}$. Os cilindros contêm diferentes alturas, podendo variar de $1,8 \mathrm{~cm}$ ou $4,3 \mathrm{~cm}$. Os cálculos de dose foram realizados nos filmes com espessura de $0,28 \mathrm{~mm}$ e com dimensões de $4 \times 4 \mathrm{~cm}^{2}$.

O objeto simulador é formado por dois conjuntos. O primeiro conjunto de placas de acrílico eram para garantir o retro espalhamento e compostos por paralelepípedos de acrílicos homogêneos. Estes tinham dimensões de $20 \times 20 \mathrm{~cm}^{2}$ e 
$20 \mathrm{~cm}$ de altura (para a fonte de ${ }^{192} \mathrm{Ir}$ ) ou de $35 \times 35 \mathrm{~cm}^{2}$ e $10 \mathrm{~cm}$ de altura (para a fonte de ${ }^{60} \mathrm{Co}$ ). O segundo conjunto pode ser dividido em objetos simuladores homogêneos e heterogêneos. Os homogêneos foram modelados por paralelepípedos inteiramente de acrílico de dimensões de $9 \times 9 \mathrm{~cm}^{2}$ e $10 \mathrm{~cm}$ de altura. Já os heterogêneos foram modelados por paralelepípedos com as mesmas dimensões do homogêneo, porém com um diâmetro de $3 \mathrm{~cm}$ para que fossem inserido os cilindros de diferentes materiais e alturas.

A fonte de ${ }^{192}$ Ir foi modelada com dois cilindros (Figura 4.9). O primeiro cilindro contém o irídio com diâmetro de 0,65mm e comprimento de 3,6 mm. Já o segundo cilindro é o encapsulamento da fonte de irídio de aço inoxidável (densidade de 22,42 $\mathrm{g} / \mathrm{cm}^{3}$ ) com diâmetro de 0,9 mm e comprimento de 4,15 $\mathrm{mm}$. Para a parte frontal da fonte foi utilizado um elipsoide (raios de 0,2 $\mathrm{mm}$ e $0,4 \mathrm{~mm}$ ) e para a final da fonte foi utilizado um tronco de cone (com diâmetro de $0,9 \mathrm{~mm}$ e altura de $0,15 \mathrm{~mm}$ ).

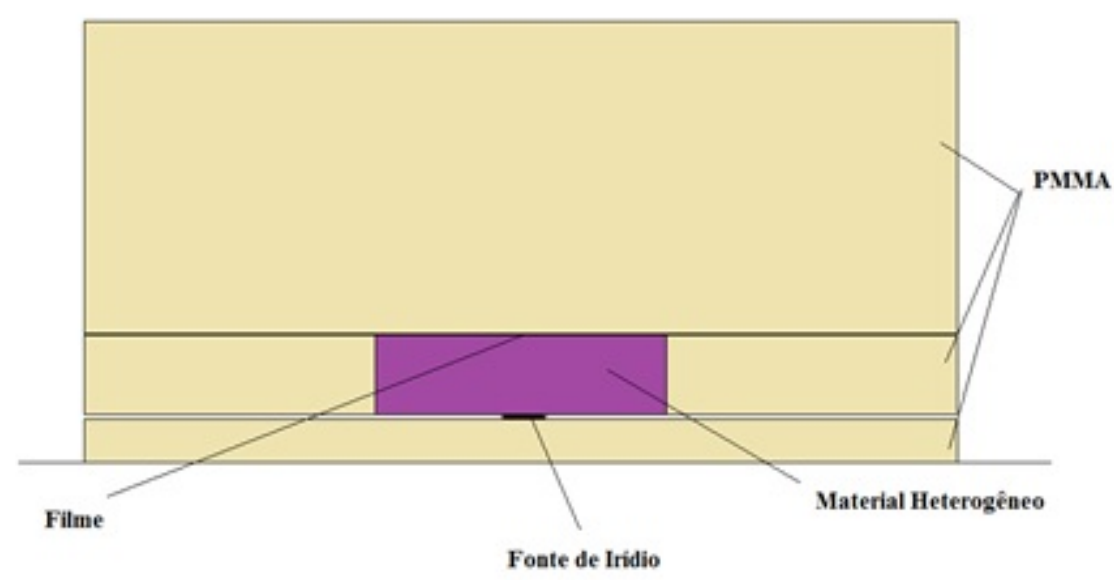

Figura 4.8: Modelagem geométrica do experimento com fonte de Irídio. 
A outra modelagem realizada foi para a fonte de ${ }^{60} \mathrm{Co}$ (Figura 4.10) com um campo de $10 \times 10 \mathrm{~cm}^{2}$. A distância fonte superfície foi de $80 \mathrm{~cm}$ e a distância fonte mesa foi de $90 \mathrm{~cm}$. A fonte tem uma angulação de $0,8^{\circ}$ para representar os colimadores do cabeçote.

Foi utilizado o tally *F8 para calcular a energia depositada em uma célula por uma fonte de fótons e elétrons. Com estes resultados foi possível encontrar o valor da dose nos filmes.

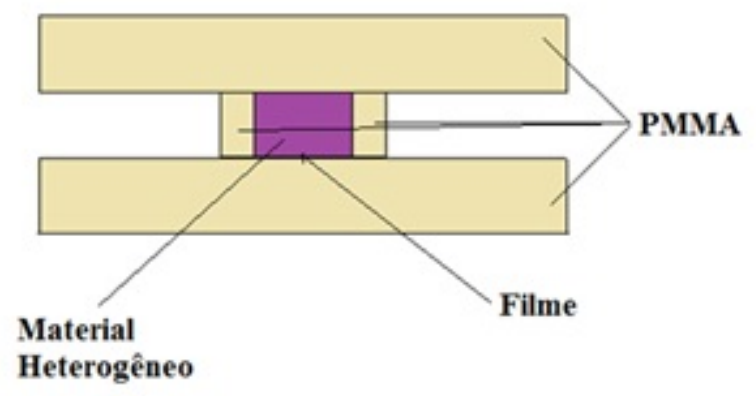

Figura 4.9: Modelagem geométrica do experimento com fonte de Cobalto. 


\section{Capítulo 5}

\section{Resultados e Discussões}

Neste capítulo estão descritos os resultados e discussões das medidas de dose e simulações do experimento.

\subsection{Materiais heterogêneos para fonte de ${ }^{192} \mathrm{Ir}$}

A dosimetria realizada neste trabalho é relativa, aos resultados de cada experimento e de cada simulação são normalizados pelo seu valor de máximo. O desvio padrão apresentado na tabela 5.1 corresponde ao maior desvio dos três filmes irradiados sob as mesmas condições.

As doses relativas puderam ser comparadas, como se pode observar nas figuras 5.1 (a) e 5.1 (b), onde estão apresentadas as curvas de calibração para as metodologias da linearização e dos multicanais. No método da linearização, a curva de calibração foi levantada com 8 pontos (Figura 5 a) dentro da faixa de 
dose que vai de 0.5 até $15 \mathrm{~Gy}$.
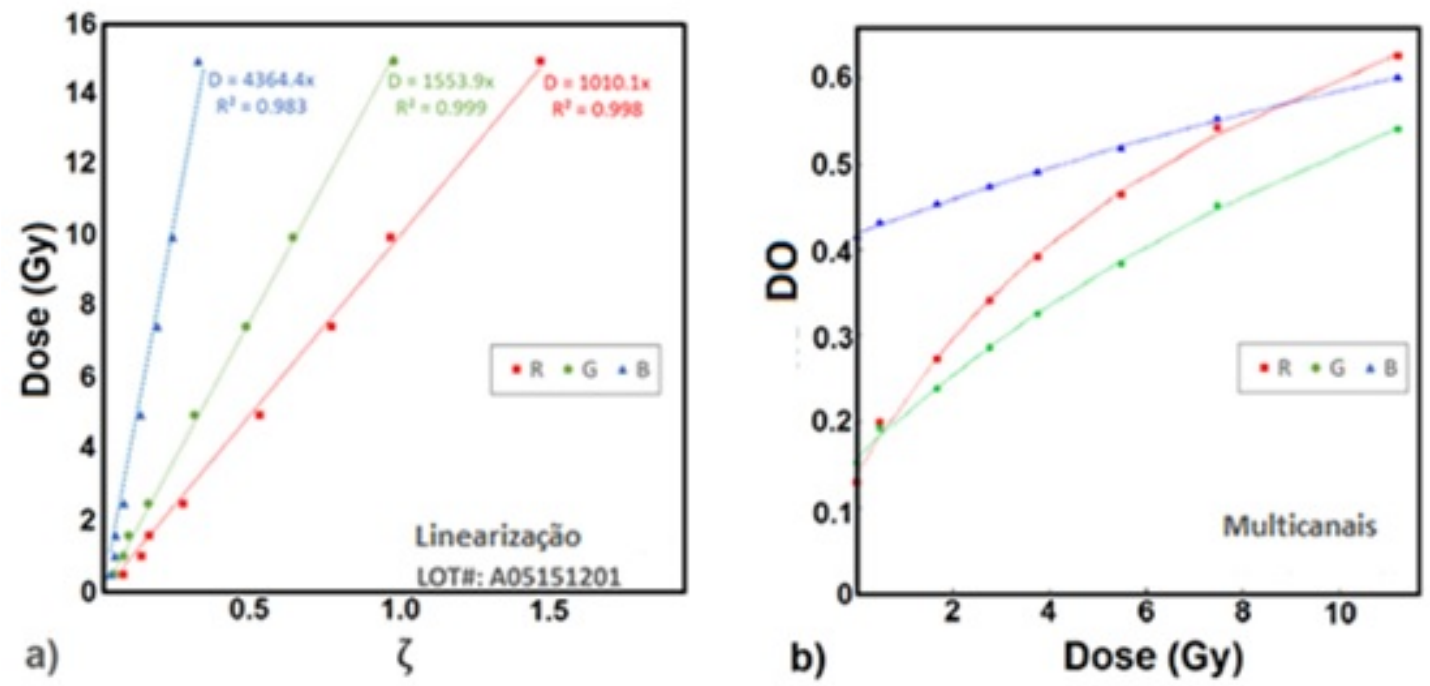

Figura 5.1: Curvas de calibração usando: a) linearização e b) multicanais.

Tabela 5.1: Incertezas obtidas a partir dos resultados experimentais e da literatura [24].

\begin{tabular}{|c|c|c|}
\hline Incerteza & Tipo A & Tipo B \\
\hline \hline Posicionamento da fonte - filme & $0,5 \%$ & \\
\hline Homogeneidade do Scanner & & $0,2 \%$ \\
\hline Reprodutibilidade do Scanner & $0,1 \%$ & \\
\hline Medida de reprodutibilidade da DO & $1,1 \%$ & \\
\hline Curva de Calibração - apenas para método dos multicanais & & $2,3 \%$ \\
\hline Dose de Referência & & $2,5 \%$ \\
\hline Média dos desvios padrão dos valores experimentais - piores casos & $4,0 \%$ & \\
\hline Incerteza total ( $(k=1)$ - linearização & $4,8 \%$ & \\
\hline Incerteza total (k=1) - multicanais & $5,4 \%$ & \\
\hline
\end{tabular}

Os resultados obtidos pelas simulações com o código MCNP5 considerando $8 \times 10^{10}$ histórias tiveram incertezas menores do que $1 \%(k=1)$. A tabela 5.1 apresenta a incerteza total das duas metodologias propostas. A incerteza da 
linerização foi de $4,8 \%$ e a incerteza do método dos multicanais foi de 5,4\% no método dos três canais. Foram feitos ajustes na curva de calibração da metodologia do multicanais para reduzir a incerteza experimental. Observa-se na tabela 5.2 uma diferença relativa entre os resultados calculados, através do código MCNP5 e os resultados experimentais. Os valores dentro dos parênteses correspondem à diferença em porcentagem (\%) entre o experimental e os valores calculados (MCNP5). Utilizandos diferentes materiais e alturas, as variações percentuais para o método da linearização foram menores que 4,6\%. Já nos resultados experimentais obtidos com o método dos multicanais as diferenças percentuais foram menores que $2,6 \%$.

Tabela 5.2: Valores de dose experimentais e calculados em cGy para diferentes materiais.

\begin{tabular}{|c|c|c|c|c|}
\hline Material & Altura $(\mathrm{cm})$ & MCNP5 & Filme (Linear) & Filme (Multicanais) \\
\hline \hline Osso 2 & 1.8 & 35.5 & $34.5(-2.8)$ & $34.7-(2.3)$ \\
\hline Pulmão ex. & 1.8 & 39.0 & $38.4(-1.5)$ & $38.0(-2.6)$ \\
\hline Pulmão in. & 4.3 & 113.1 & - & - \\
\hline Adiposo & 4.3 & 95.3 & $99.7(4.6)$ & - \\
\hline Mama & 4.3 & 94.4 & - & - \\
\hline Músculo & 4.3 & 92.3 & $92.1(-0.3)$ & - \\
\hline PMMA & 4.3 & 90.5 & $88.8(-1.9)$ & - \\
\hline Osso 1 & 4.3 & 90.8 & - & - \\
\hline Osso 3 & 4.3 & 72.4 & - & - \\
\hline
\end{tabular}

As medidas de dose com fontes de braquiterapia são particularmente complexas, devido ao elevado gradiente de dose, o que pode conduzir a elevadas diferenças experimentais. Em termos gerais, os resultados apresentados tem uma boa concordância. Em alguns materiais não foi possível realizar as devidas 
comparações devido a falta de experiência em realizar os experimentos e também no uso das duas metodologias. A linearização é mais simples para a obtenção dos resultados e apresentou uma incerteza inferior. No caso da metodologia de multicanais existe uma complexidade maior nos cálculos computacionais fazendo com que reduza o efeito de componentes relacionados a não-dose, como a variação da espessura da camada ativa e a presença de sujeira.

\subsection{Estudos comparativo entre a calibração de uma fonte de ${ }^{192}$ Ir e um Acelerador Linear}

O estudo das metodologias de dosimetria com filme EBT3 foi realizado através da obtenção da curva de calibração. O resultado da calibração dos filmes irradiados está apresentado na Figura 5.2. As curvas de calibração apresentam variações em razão do espectro energético das fontes utilizadas nas calibrações usando ambas as metodologias com o feixe de fótons de $6 \mathrm{MV}$ e ${ }^{192} \mathrm{Ir}$. Com isso, devido à dependência energética dos filmes faz-se necessária uma calibração com a mesma fonte utilizada nos experimentos.

Na Figura 5.3 são apresentadas razões entre os valores de dose obtidos e o valor esperado. Cada ponto corresponde a uma média dos resultados obtidos com três filmes e seu respectivo desvio padrão (Tipo $A, \pm 1 \sigma$ ). No método 
da linearização apenas o canal verde foi avaliado, uma vez que o canal verde apresenta melhores resultados para as doses utilizadas. Isto pode ser notado pela figura 5.2, uma vez que os valores dos canais vermelho e azul estão fora do ajuste linear para as doses abaixo de $5 \mathrm{~Gy}$.
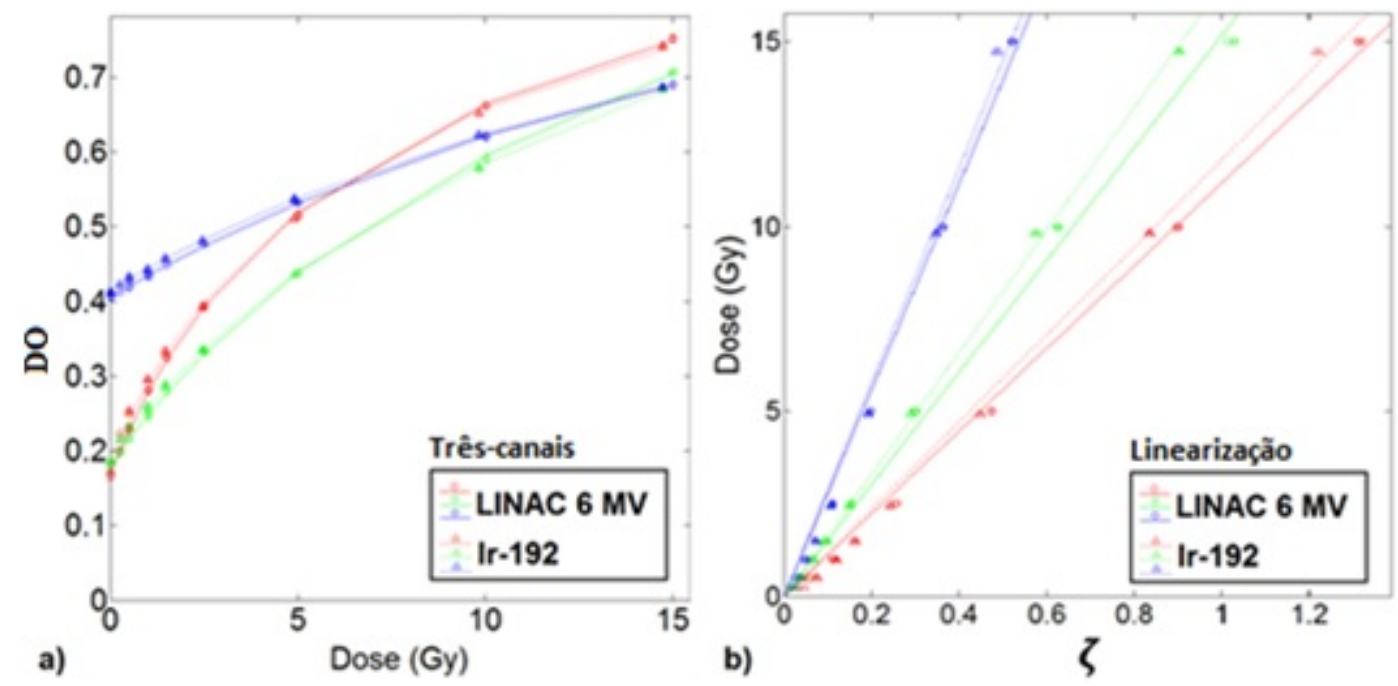

Figura 5.2: Curvas de calibração obtidas com método dos três canais (a) e com o método da linearização (b) para dois tipos de fonte: acelerador linear de $6 \mathrm{MV}$ e fonte de ${ }^{192} \mid r$. 

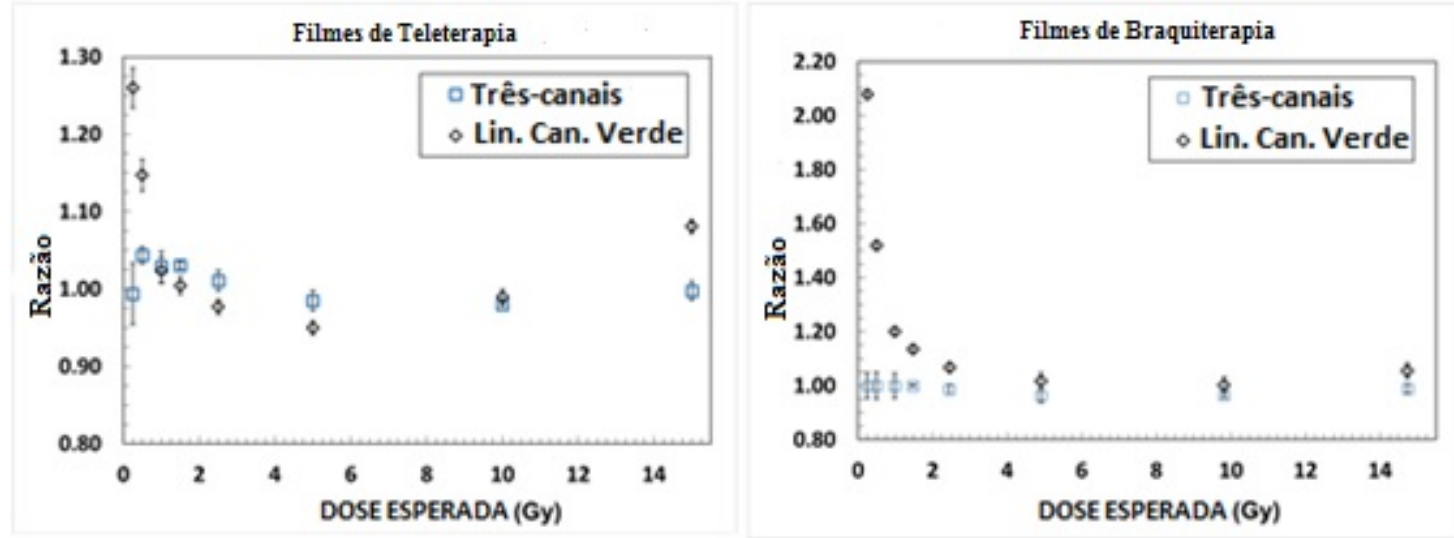

Figura 5.3: Razão entre as doses obtidas experimentalmente e os valores esperados para a calibração realizada com duas fontes distintas. a) Acelerador linear $6 \mathrm{MV}$ (teleterapia); b) ${ }^{192}$ Ir (braquiterapia).

O intuito de traçar as curvas das figuras 5.2 e 5.3 é verificar as metodologias para braquiterapia, uma vez que se utiliza como referência os dados do acelerador linear e assim comparar com as curvas obtidas com a fonte braquiterapia.

O método dos multicanais uniformiza a resposta dos três canais, como pode ser observado na Figura 5.4 onde são apresentadas distribuições de dose para os três canais (RGB) sem a correção (linha superior) e após a correção da não dose proposto pelo método dos multicanais. 


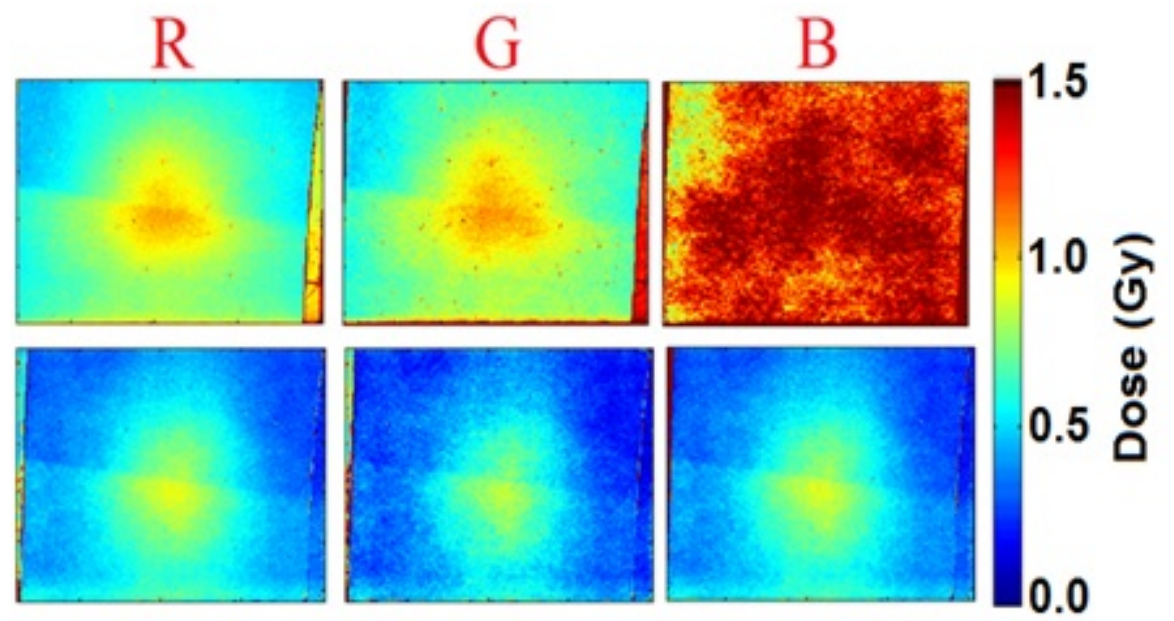

Figura 5.4: Distribuição de dose obtida para os três canais (RGB) sem correção (linha superior) e após a correção.

Os resultados obtidos com os três canais, após a correção, são mais homogêneos e apresentam menos ruído (Figura 5.4), uma vez que a metodologia proposta reduziu parte do ruído proveniente da poeira sobre o filme. Na Figura 5.5a (picos de dose antes da correção) e Figura 5.5b (picos de dose após da correção) é possível observar que os canais não respondem da mesma forma a presença da poeira com variações de até 0,6 Gy, permitindo a redução do ruído proveniente da mesma. 

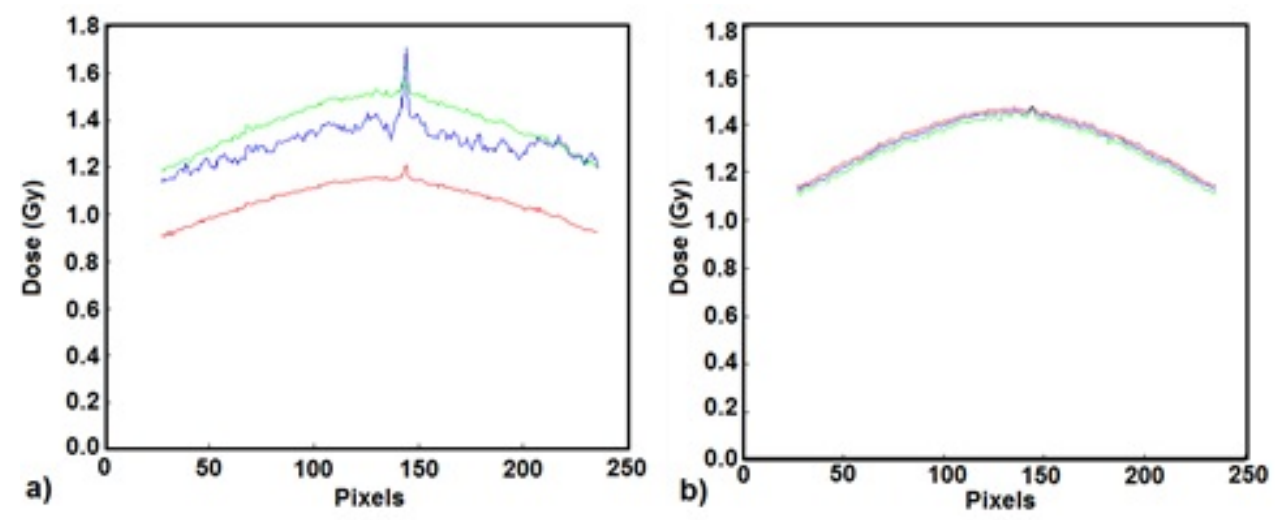

Figura 5.5: Perfis de dose antes (a) e após (b) a correção.

A partir dos filmes irradiados foi possível realizar uma comparação entre as duas metodologias propostas, como pode ser observado na Figura 5.6. É possível observar maior concordância para doses mais altas e na região central onde a razão entre elas é de 1,0, com deslocamentos das isodoses aumentando para doses mais baixas variando a razão entre 1,1 e 1,2. Os valores das curvas de isodoses correspondem à dose em Gy. 

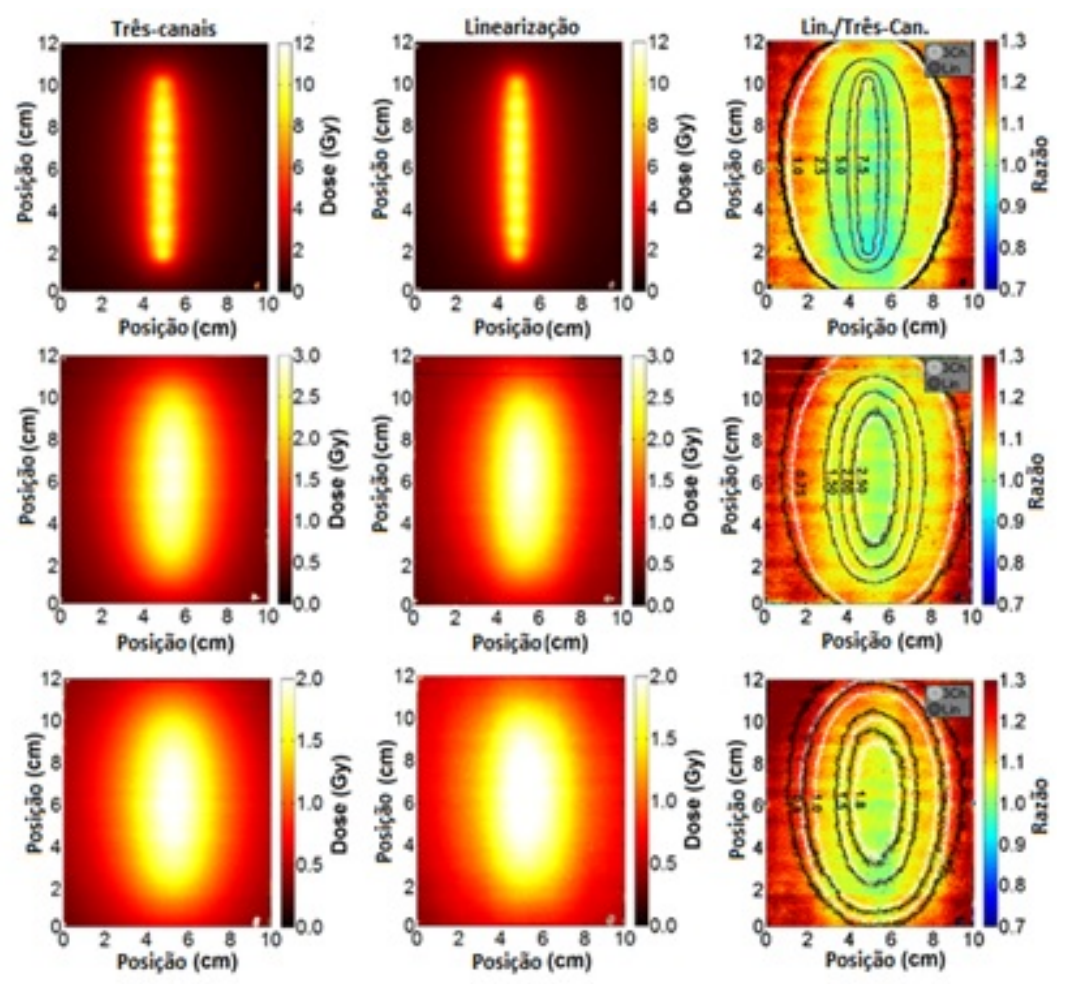

Figura 5.6: Doses obtidas com o método dos três canais (primeira coluna), da linearização (segunda coluna) e a razão entre os resultados (terceira coluna).

As irradiações com o acelerador linear são mais rápidas e possuem menor incerteza, uma vez que feixes com energias mais altas possuem menor gradiente de dose. Isto faz com que haja uma redução nas variações da resposta em razão da incerteza do posicionamento e também pelo tamanho do campo, permitindose utilizar o valor médio numa região do filme irradiado. Os experimentos que utilizam fontes de braquiterapia são particularmente complexos, devido ao elevado gradiente de dose, o que pode conduzir a elevadas diferenças experimentais.

A linearização é mais simples, mas não apresentou boa conformidade com os valores esperados, sobretudo para baixas doses, com variações de até $210 \%$.

O método dos multicanais não requer uma curva de calibração apenas en- 
contrar os valores das constantes de calibração e apresentou variação máxima de $5 \%$. Como o multicanal pode reduzir o efeito de componentes relacionados a não dose, isso pode gerar a variação encontrada durante o trabalho.

\subsection{Materiais heterogêneos para a fonte de ${ }^{60} \mathrm{Co}$}

O resultado da calibração dos filmes irradiados para a fonte de ${ }^{60}$ Co está apresentado na figura 5.7. As curvas de calibração apresentam variações em razão das metodologias com o feixe de fótons do ${ }^{60} \mathrm{Co}$. Com isso, devido à dependência energética dos filmes faz-se necessária uma calibração com a mesma fonte utilizada nos experimentos. No método da linearização os valores são considerados quando apresentam um valor de $\mathrm{R}^{2}$ igual ou superior a 0.999 . Os valores dos $\mathrm{R}^{2}$ dos canais vermelho, verde e azul são 0,999, 0,9994 e 0,9955, respectivamente.
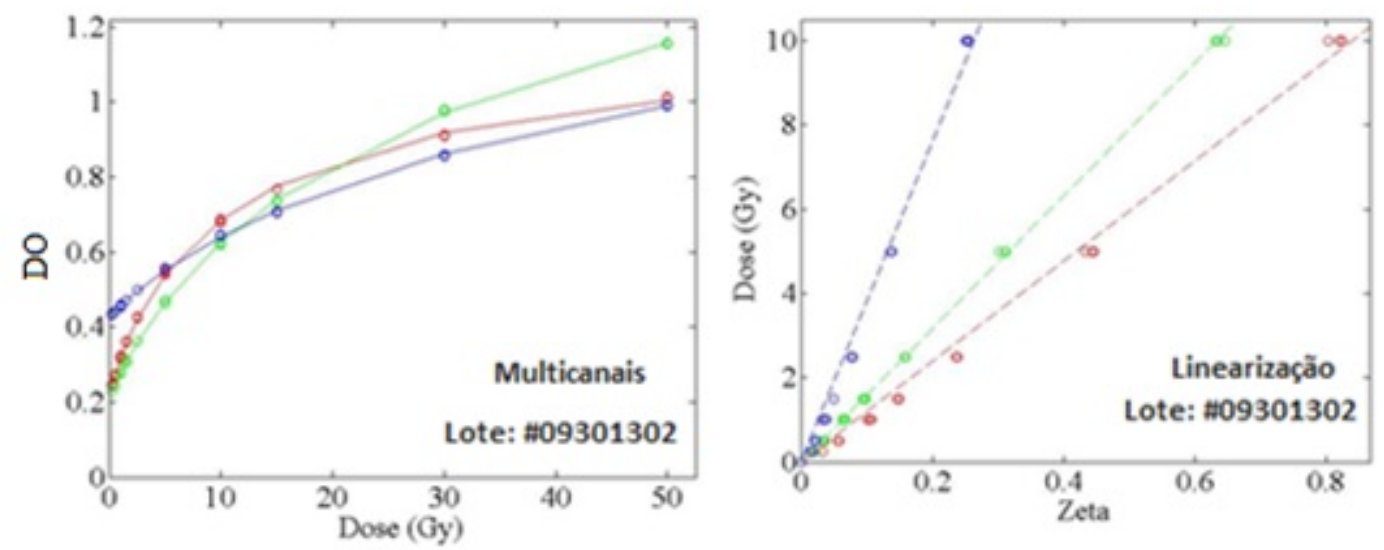

Figura 5.7: Curvas de calibração obtidas com método dos três canais (a) e com o método da linearização (b). 
Na tabela 5.3 são apresentadas razões entre os valores de dose obtidos e o valor esperado usando os materiais heterogêneos. Cada ponto corresponde a uma média dos resultados obtidos com três filmes. No método da linearização o canal verde apresentou os melhores resultados e também quando comparados com a simulação. As medidas em cinza é uma combinação entre os três canais de cores.

Devem ser considerados erros experimentais tais como: a) deslocamento do filme durante a exposição; b) o volume do detector (espessura do filme) comparado ao volume do cilindro modelado no input da simulação no código MCNP5; c) efeito de borda que ocorre na periferia da fonte, ou seja, o tamanho do campo $10 \times 10 \mathrm{~cm}^{2}$.

As incertezas da metodologia da linearização ficaram de 0,58 a $0,92 \%$ para o canal vermelho, de 0,32 a 0,50\% para o canal verde e de 0,51 até 0,57\% para o canal azul. E a incerteza da metodologia dos multicanais foram de 0,77\% a 1,14\%. Já as incertezas dadas pela simulação utilizando o código MCNP5 para um número de histórias de $8 \times 10^{10}$, foram menores do que $1 \%$.

Tabela 5.3: Valores de dose experimentais e calculados em Gy para diferentes materiais.

\begin{tabular}{|c|c|c|c|c|c|c|}
\hline Material & $\mathrm{R}$ & $\mathrm{G}$ & $\mathrm{B}$ & CINZA & Multicanais & MCNP \\
\hline PMMA & 2,44 & 1,99 & 2,53 & 2,18 & 2,34 & 2,00 \\
\hline Osso & 1,88 & 1,51 & 1,88 & 1,65 & 1,81 & 1,51 \\
\hline Pulmão & 2,71 & 2,22 & 2,73 & 2,44 & 2,67 & 2,27 \\
\hline
\end{tabular}

Na tabela 5.4 são apresentadas diferenças percentuais entre os valores de 
dose obtidos e o valor esperado usando os materiais heterogêneos. Os valores correspondem a uma comparação entre o PMMA, pulmão e osso. Os valores do canal verde apresentaram os melhores resultados quando comparados com os valores obtidos pelo MCNP5.

Tabela 5.4: Diferenças percentuais na dose para diferentes materiais.

\begin{tabular}{|c|c|c|c|c|c|c|}
\hline Material & $\mathrm{R}$ & $\mathrm{G}$ & $\mathrm{B}$ & CINZA & Multicanais & MCNP \\
\hline \hline PMMA & 0,00 & 0,00 & 0,00 & 0,00 & 0,00 & 0,00 \\
\hline Osso & $-22,84$ & $-23,90$ & $-25,74$ & $-24,41$ & $-22,51$ & $-24,30$ \\
\hline Pulmão & 10,87 & 11,31 & 8,11 & 11,96 & 13,88 & 13,66 \\
\hline
\end{tabular}

As irradiações com o ${ }^{60} \mathrm{Co}$ fazem com que haja uma redução nas variações do posicionamento e também pelo tamanho do campo, permitindo utilizar o valor médio numa região do filme irradiado.

A linearização é mais simples, mas não apresentou boa conformidade para o canal azul com os valores esperados, sobretudo para baixas doses, com variações de até $150 \%$. Já no canal verde, as variações de até $50 \%$ para doses menores que 1 Gy e para doses acima a variação de até $10 \%$ apresentando uma boa conformidade. No caso do canal vermelho, as variações de até $60 \%$, principalmente, para as doses baixas.

O método dos multicanais apresentou variação máxima de até $2 \%$. As diferenças causadas nas respostas obtidas pelos dois métodos podem estar relacionadas com os componentes da não dose reduzidos pela metodologia dos multicanais. 


\section{Capítulo 6}

\section{Conclusão}

Neste trabalho foi proposta a caracterização dosimétrica do filme radiocrômico EBT3 lançado, em 2012, no mercado para fontes de braquiterapia. Esses filmes radiocrômicos apresentam alta resolução espacial e alta sensibilidade. O manuseio destes filmes se deu de forma rápida, prática e eficaz. A caracterização dosimétrica do filme EBT3 consistiu na determinação da curva reposta do filme e os resultados comparados com o do código MCNP5, que é baseado no método de Monte Carlo.

O método da linearização foi utilizado neste trabalho para medidas de dose, no qual apresentaram uma reprodutibilidade razoável em suas respostas, uma vez que o efeito da não dose não pode ser retirado durante a análise. É uma metodologia bem simples que pode ser claramente observada em suas equações apresentadas.

A metodologia do multicanais utilizou o software desenvolvido no MATLAB 
que serviu para a resolução de cálculos complexos e repetitivos. Comprovou se pelas imagens mostradas nos experimentos que é possível a retirada da componente não-dose e que tem uma grande diferença nas medidas. Apesar da dificuldade das equações a metodologia apresentou se eficiente para dosimetria destes tipos de fontes radioativas.

Neste trabalho foi possível verificar que, segundo o fabricante, os limites de dose para cada canal, sendo para o canal vermelho de até $8 \mathrm{~Gy}$, canal verde de 8 até 40 Gy e o canal azul fornece um sinal de resposta para a melhoria da uniformidade automática do filme. Já pelo experimento nota-se que estes limites de dose são diferentes para canal vermelho que foi de até 1Gy, para o verde de 1 até 10 Gy e para o canal azul de 10 até 40 Gy. Uma explicação para essa diferença são as metodologias aplicadas para medida de dose.

A sistemática de simulação com o MCNP5 apresentada neste trabalho, pela sua praticidade e simplicidade, aparece como uma poderosa e ágil ferramenta para conferência e confirmação das características dosimétricas fornecidas pelos fabricantes destes aplicadores, e utilizadas na rotina dos serviços de radioterapia, otimizando significativamente as atribuições dos físicos responsáveis por estes procedimentos.

O código MCNP5 foi utilizado neste trabalho a fim de se obter a dose em objetos simuladores homogêneos e heterogêneos, onde estes resultados calculados pudessem ser comparados com os resultados das medidas experimentais realizadas com as fontes de ${ }^{60} \mathrm{Co}$ e de ${ }^{192} \mathrm{Ir}$. De uma forma geral pode-se dizer 
que os resultados obtidos por meio de cálculos apresentaram-se equivalentes aos resultados experimentais.

O formalismo do TG-43 para a dose em braquiterapia proporcionou especificações da fonte e cálculo de dose que tornou mais fácil as comparações entre dose-resposta. Por enquanto, o TG-43 contribuiu para a estrutura com recomendações específicas do campo da braquiterapia. Já a aplicação do TG-186 ajudou a garantir uma busca de melhores ferramentas para o cálculo da dose.

Além disso, a maioria dos experimentos dosimétricos em braquiterapia é com transporte de radiação e deposição de energia e com dose na água (calculado nos termos da abordagem TG-43). Por isso, foi incluindo o impacto sobre a dose prescrita em pontos como órgãos e outras regiões de interesse. Isto permitiu uma avaliação das implicações adotadas pelo MCNP5 para compreender os resultados.

Este trabalho como um todo conseguiu atingir todos os seus objetivos, desde a obtenção e análise das doses, onde foram validados os dois tipos de softwares e as duas metodologias. 


\section{Capítulo 7}

\section{Referências Bibliográficas}

[1] CAMPOS, L. T. Controle de Qualidade de Planejamento de Tratamentos Radioterapêuticos com Feixes de Elétrons. 2010. 136 p. Tese de Doutorado (Programa de Pós-graduação em Engenharia Nuclear COPPE) - Universidade Federal Do Rio de Janeiro, Rio de Janeiro, 2010.

[2]SERRA, J.; SOUZA, R.R.; KLIGERMAN, J.; MORAES, M.; ARAÚJO, A.N.C.; GUIZZARDI, M. Programa de Qualidade em radioterapia - curso de atualização para técnicos em radioterapia. INCA, PQRT. 1 curso Disponível em: http://www.inca.gov.br/pqrt/download/trab/minicurso_radioprotecao_aula1.pdf. Acessado em 05/03/2013.

[3] PODGORSAK, E.B. Radiation oncology Physics: A Handbook for Teachers and Students. Vienna: IAEA, 2005.

[4] Palmer, A. L.; Nisbet, A.; Bradley, D. Verification of high dose rate brachytherapy dose distributions with EBT3 Gafchromic film quality control te- 
chniques. Phys. Med. Biol. 58, 497-511 (2013)

[5] Coelho, T. S. Desenvolvimento de um Sistema de Dosimetria para Aplicadores de Betaterapia de 90Sr+90Y. 2010. 107 p. Dissertação de Mestrado (Mestrado em Ciências na Área de Tecnologia Nuclear - Reatores) - IPEN/SP.

[6] QUEZADA, V.A.C. Estabelecimento de um sistema dosimétrico para altas doses utilizando vidros. Dissertação de Mestrado, IPEN/SP -1997.

[7] DA SILVA, Rosemeire Evangelista. Dosimetria com Materiais Radiocrômicos em Feixes de Elétrons Acelerados - Processos de Irradiação com Doses Altas. 2000. 132 p. Dissertação de Mestrado (Mestrado em Ciências na Área de Reatores Nucleares de Potências e Tecnologia do Combustível Nuclear) - IPEN/SP, São Paulo, 2000.

[8] M. J. Butson, T. Cheung, and P.K. Yu, "Weak energy dependence of EBT Gafchromic film dose response in the 50kVp-10MVp x-ray range" Appl.Radiat. Isot. 64, 60-62 (2006).

[9] G. Massilon-JL, S. Chiu-Tsao. Domingo-Murioz, and M. F. Chan, "Energy dependence of the new Gafchromic EBT3 film - Dose response curves 50kV, 6 and 15 MV x-ray beams", Int. J. Med. Phys. Clin. Eng. Rad. Oncol. 1, 60-65 (2012)

[10] DEVIC, Slobodan et al. Linearization of dose-response curve of the radiochromic film dosimetry system. Medical Physics, v. 39, n. 8, p. 4850-4857, ago. 2012.

[11] SCAFF, L.A.M. Física na Radioterapia. 1.ed. São Paulo, SP.: Projeto 
Saber, 2010.

[12] OKUnO, E.; YOSHIMURA, E. Física das Radiações. 1.ed. São Paulo, S.P.: Oficina de Textos, 2010

[13] ROSTElATO, M. E. C. M. Preparação de fontes de irídio-192 para uso em braquiterapia. 1997. Dissertação (Mestrado) - Instituto de Pesquisas Energéticas e Nucleares, São Paulo.

[14] KASE, K. R.; BJARNGARD, B. E.; ATTIX, F. H. The dosimetry of ionizing radiation. New York: Academic, 1990. v.3.

[15] BRIDGE, L. R.; MARSHALL, D. S. C; WILSON, W. P. A Technique for the Loading of Iridium 192 Wire. Br. J . Radiol., v. 54, p.907-908, 1981.

[16] CRUZ, J. C.; OLIVEIRA, V. C.; PEREZ, C. A.; KALNICKI, S. Implantes intersticiais com Indio -192.

[17] Nath R., Anderson L.L.; Luxton G., Weaver K. A.; Williamson J.F.;Meigooni, A.S.; Dosimetry of interstitial brachytherapy souces: Recommendations of the AAPM Radiation Therapy Committee Task Group No. 43. Medical physics, vol. 22, no. 2, p. $209-234,1995$.

[18] Moura, E.S.; Desenvolvimento de um objetivo simulador para investigação de heterogeneidade em Braquiterapia de alta taxa de dose. 2015. Dissertação (Doutorado) - IPEN/SP.

[19] Beaulieu L; Tedgren AC; Carrier JF; Davis SD; Mourtada F; Rivard MJ; Thomson RM; Verhaegen F. (2012). Report of the Task Group 186 on modelbased dose calculation methods in brachytherapy beyond the TG-43 formalism: 
Current status and recommendations for clinical implementation. Medical Physics 39: 6208-6236.

[20] Chair, A.N.R.; Blackwell, C.R.; Coursey, B.M.; Gall, K.P.; Galvin, J.M.; McLaughlin, W.L.; Meigooni, A.S.; Nath R.; Rodgers, J.E.; Soares, C.G. Radiochromic film dosimetry: Recommendations of AAPM Radiation Therapy Committee Task Group 55. Med. Phys. 25, 2093-21115 (1998).

[21] CARDOSO, M. A. C. Estudo de distribuição de dose em tratamento por radiocirurgia usando fantoma antropomórfico e filme radiocrômico. 2012. Dissertação (Mestrado) - Universidade Federal do Rio de Janeiro, Rio de Janeiro.

[22]http://www.ashland.com/Ashland/Static/Documents/ASI/Advanced\%20Materials/8 ebt3.pdf. Acessado em: 18/06/2015.

[23] Carvalho, A.L.S.; Implementação de um sistema de dosimetria "in-vivo" em Radioterapia Externa - aplicação no cancro da mama. 2009. Dissertação (Mestrado) - Universidade do Minho, Guimarães, Portugal.

[24] LEWIS, David et al. An efficient protocol for radiochromic film dosimetry combining calibration and measurement in a single scan. Medical Physics, v. 39, n. 10, p. 6339-6350, 2012.

[25] WHITMORE, W. F.; HILLARIS, B.; GRABSTALD, H. Retropubic implantation of iodine-125 in the treatment of prostatic cancer. J. Urol., v. 108, p. $918,1972$.

[26] Batista, B. J. B. Avaliação de dosímetros termoluminescentes para uso em radioterapia com fótons de alta energia. 2011. Dissertação (Mestrado) - 
Instituto de Física, São Paulo.

[27] FERREIRA, T.A.; RASBAND, W. The ImageJ User Guida version 1.43. IMAGE PROCESSING AND ANALYSIS IN JAVA. 2010. Disponível em: <http://rsbweb.nih.g guide.pdf>. Acessado em: 10 março 2013.

[28] Matsumoto, E.Y.; MATLABß7 Fundamentos. 2.ed. São Paulo, S.P.: Érica, 2008.

[29] DEVIC, Slobodan et al. Linearization of dose-response curve of the radiochromic Im dosimetry system. Medical Physics, v. 39, n. 8, p. 4850-4857, ago. 2012.

[30] Fonseca, G.P.; Luvizotto, J.; Coelho, T.S.; Antunes, P.C.G.; Rubo R.; Siqueira, P.T.D; Yoriyaz, H.; (2013). Brachytherapy dose measurements in heterogeneous tissues. International Symposium on Solid State Dosimetry (ISSSD).

[31] Micke A; Lewis DF; Yu X. (2011). Multichannel film dosimetry with nonuniformity correction. Medical Physics 38: 2523-2534.

[32] YORIYAZ, H. Monte Carlo Method: principles and applications in Medical Physics. Revista Brasileira de Física Médica, v. 1, n. 1, p. 141-149, 2009.

[33] Fonseca, G. P.; Projeto e construção de placas espalhadoras e degradadoras de energia para uso em radioterapia com feixes de elétrons para doenças de pele. 2010. Dissertação (Mestrado) - IPEN/SP.

[34] OAK RIDGE NATIONAL LABORATORY. MCNP5-I Monte Carlo NParticle Transport Code System; RSICC Computer Code Collection, Los Alamos 
National Laboratory, Los Alamos, New México, 2000.

[35] Albuquerque, F.P.; CÁLCULO DOS COEFICIENTES DE CONVERSÃO DE KERMA NO AR PARA EQUIVALENTE DE DOSE AMBIENTE PARA FEIXES DE RAIOS X UTILIZADOS EM RADIODIAGNÓSTICOS. 2007. 82 p. Dissertação de Mestrado (Mestrado em Ciências na Área de Engenharia Nuclear) - COPPE/UFRJ/RJ.

[36] PEREZ-CALATAYUD, Jose et al. Dose calculation for photon-emiting brachytherapy sources with average energy higher than $60 \mathrm{keV}$ : Report of the AAPM and ESTRO. Medical Physics, v. 39, n. 5, p. 2904-2929, 2012.

[37] TAUHATA, L.; SALATI, I.P.A.; PRINZIO, R.Di; PRINZIO, A.R.Di. Radioproteção e Dosimetria: Fundamentos. 5. revisão. Rio de Janeiro, R.J.: IRD/CNEN,2003.

[38] Elbern, A.; Noções básicas de braquiterapia, Pro Rad. 1 curso Disponível em: http://www.prorad.com.br/downloads/Radioterapia-2.pdf. Acessado em: 22 de agosto de 2013.

[39] KHAN, F.M.; The physics of radiation therapy. 3.ed. Philadelphia, P.A.: Lippincott Williams \& Wilkins, 2003.

[40] Rivard MJ; Coursey BM; DeWerd LA; Hanson WF; Huq MS; Ibbott GS; Mitch MG; Nath R; Williamson JF. (2004). Technical Report 84 - Update of AAPM Task Group No. 43 Report: A revised AAPM protocol for brachytherapy dose calculations. Medical Physics 31: 633-674.

[41] ALDELAIJAN S; MOHAMMED H; TOMIC N; LIANG L; DEBLOIS F; 
SARFEHNIA A; ABDEL-RAHMAN W; SEUNTJENS J; DEVIC S. (2011). Radiochromic film dosimetry of HDR 192Ir source radiation fields. Medical Physics 38: $6074-6083$.

[42] HILARIS, B. S.; MASTORAS, D. A.; SHIH, L. L.; BODNES, W. R. History of brachytherapy: the years after the discovery of radium and radioactivity. In: Nag, s. Principles and practice of brachytherapy. N. Y.: Futura Publishing Company Inc, 1997.

[43] OLIVEIRA, V. C.; SOARES, W. E.; SALVAJOLI, J. V.; PERES, 0. MORALES, F. C.; FUJISAWA, S ; TAMONI, F. M. A. Iridium, terapia versátil, táticas e técnicas. Radiol. Bras., v.15, n.1, p. 44-48, 1982.

[44] GODDEN, T. J. Physical aspects of brachytherapy. Bristol: Adam Hilger, 1988. (Medical Physics Handbooks 19).

[45] BERNSTEIN, M.; GUTIN, P. Interstitial irradiation of brain tumors. Neurosurgery, v. 9, n. 6, p. 741-750, 1981.

[46] FERNANDES, M. A. R. Utilização de moldes radioativos especiais de foIhas de ouro-198 para braquiterapia em tumores de pele. 2000. Tese (Doutorado) - Instituto de Pesquisas Energéticas e Nucleares, São Paulo.

[47] GERBAULET, A.; HAIE-MEDER, C.; CHASSAGNE, D. Role de la curiethérapie dans le traitment des cancers gynécologiques. Bull. Cancer, v. 77, p. $245-250,1990$.

[48] PORTER, A. T. Prostate brachytherapy an overview. In: BRACHYTHERAPY MEETING - REMOTE AFTERLOADING: STATE OF THE ART, May 
4-6, 1989, Michigan. Proceedings...US A, 1989. p. 267-280. ]

[49] PINTO, A. C. A história da braquiterapia. A radioterapia no Brasil. Curitiba: Liga Paranaense de Combate ao Câncer, 1995.

[50] PIERQUIN, B.; CHASSAGNE, D.; COX, J. D. Toward consistent local control of certain malignant tumors. Radiol. v. 99, n. 3, p. 661 - 667, 1971.

[51] CARLTON, C. E.; DAWOUD, F.; HUDGINS, P. T. Irradiation treatment of carcinoma of the prostate. J. Urol., v. 108, p. 924, 1972.

[52] HAZLETON-NUCLEAR SCIENCE CORPORATION. Donald C. Lawrence. Therapeutic metal seed containing within a radioactive isotope disposed on a carrier and method of manufacture. US Pat. n. 3,351,049, 7 nov. 1967.

[53] RUSSEL, J. A century of brachytherapy. Nucl. News, p. 44-46, Dec. 2004.

[54] LAWTON, C.; ROSEN, M.; GILLIN, M.; STUTZ, M. Prostate brachytherapy. Wisconsin: Medical College of Wisconsin, 1996.

[55] PORTER, A.; BLASKO, J. C.; GRIMM, P. D.; REDDY, S. M.; RADGE, H. Brachytherapy for prostate cancer. Califórnia: ACS, 1995. v.45.

[56] HOLM, H. H. The history of interstitial brachytherapy of prostatic cancer. Semin. Surg. Oncol., v. 13, n. 6, p. 431 ^ $37,1997$.

[57] ROSTElato, M. E. C. M. Estudo e desenvolvimento de uma nova metodologia para confecção de sementes de lodo-125 para aplicação em braquiterapia. 2005. Dissertação (Doutorado) - Instituto de Pesquisas Energéticas e Nucleares, São Paulo. 
[58] SALVAJOLI, J.V.; SOUHAMI, L.; FARIA, S.L. Radioterapia em Oncologia. 1.ed. Rio de Janeiro, R.J., 2006. 